\title{
Accuracy of three-dimensional virtual simulation of the soft tissues of the face in OrtogOnBlender for correction of class II dentofacial deformities: an uncontrolled experimental case-series study
}

\author{
Hugo Santos Cunha ${ }^{1} \cdot$ Cícero André da Costa Moraes $^{2} \cdot$ Rodrigo de Faria Valle Dornelles $^{3} \cdot$ \\ Everton Luis Santos da Rosa ${ }^{4}$ (D)
}

Received: 7 June 2020 / Accepted: 30 October 2020 / Published online: 8 November 2020

(C) Springer-Verlag GmbH Germany, part of Springer Nature 2020

\begin{abstract}
Purpose To assess whether virtual simulations of the projection of the soft tissues of the face after class II bimaxillary orthognathic surgery, generated from 3D reconstruction of preoperative computed tomography (CT) scans, differed significantly from the actual soft tissue profile obtained in the late postoperative period (beyond 6 months). Secondarily, to validate the accuracy of a free, open-source software suite for virtual soft tissue planning in orthognathic surgery.

Methods Helical CT scans were obtained pre- and postoperatively from 16 patients with Angle class II malocclusion who underwent bimaxillary orthognathic surgery. A comparative study between soft tissue meshes constructed for surgical simulation (M1) and the actual meshes obtained from postoperative scans (M2) was then performed. To establish the accuracy of 3D facial soft tissue simulation in a free and open-source software suite (OrtogOnBlender-OOB), 17 predetermined anatomic landmarks were measured in M1 and M2 scans after alignment of cranial structures.

Results The mean error between preoperative simulations and actual postoperative findings was $<2 \mathrm{~mm}$ for all anthropometric landmarks. The overall average error for the facial soft tissues was $1.07 \mathrm{~mm}$.

Conclusion Comparison between preoperative simulation (M1) and actual postoperative findings (M2) showed clinically relevant ability of the method to reproduce actual surgical movement reliably $(<2-\mathrm{mm}$ error). OOB is capable of accurate soft tissue planning for orthognathic surgery, but mesh deformation methods still require improvement.

Trial registration RBR-88jff9. Retrospectively registered at Brazilian Registry of Clinical trials-ReBec (http://www. ensaiosclinicos.gov.br) May 06, 2020.
\end{abstract}

Keywords 3D simulation $\cdot$ Soft tissue simulation $\cdot 3 \mathrm{D}$ imaging $\cdot$ Computer simulation $\cdot$ Orthognathic surgery

Everton Luis Santos da Rosa

zazai547@gmail.com

1 Oral and Maxillofacial Surgery Unit, Hospital de Base do Distrito Federal, Brasília, DF, Brazil

2 Ortogonline Treinamento em Desenvolvimento Profissional e Consultoria Ltda, Sinop, MT, Brazil

3 Hospital Beneficência Portuguesa de São Paulo, São Paulo, SP, Brazil

4 Oral and Maxillofacial Surgery Unit, Instituto de Gestão Estratégica de Saúde do Distrito Federal (IGESDF), Hospital de Base, SMHS Área Especial, Q. 101 - Asa Sul, Brasília, DF 70330-150, Brazil

\section{Introduction}

Facial appearance is an important factor in personal relationships and affects social and psychological development [1]. Orthognathic surgery aims to correct discrepancies in the skeletal and soft tissues of the face to achieve esthetic and functional results in patients with jaw disharmony [2-4].

Correction of these deformities with orthognathic surgery does not always result in an ideal soft tissue appearance, because there is no exact proportionality between soft tissue movements and those of the underlying bones [5, 6]. Thus, if achieving facial harmony is desired, the focus should be on the final soft tissue changes [7,8].

Knowledge of the soft tissue response to skeletal changes not only helps guide the surgical movement of 
the osteotomized segments but also plays an important role in communication between the surgeon, the orthodontist, and the patient $[9,10]$. Some studies have shown that simulation of the final result allows patients to understand how they will look after the procedure and thus match their expectations with the achievable surgical outcome $[11,12]$.

Two-dimensional (2D) planning is of limited value for prediction of facial soft tissue changes [13]. With accelerated advancement and wider dissemination of simulation technology, research has begun to shift toward three-dimensional (3D) evaluation of soft tissue changes as the norm in orthognathic surgery [14-18]. For more than 20 years, investigators have been developing computer software to simulate soft tissue movements in orthognathic surgery, sometimes aided by capture of 3D images of the face (e.g., stereophotogrammetry, pulsed light, and laser scanners) [19-26].

Some algorithms have been developed and incorporated into commercially available predictive software packages to quantify changes in facial soft tissues in three dimensions [3, 17, 18, 27-30].

Existing commercial programs use soft tissue deformation methods to simulate the outcome on a face mesh, such as the mass spring model [28, 30], TPS-RPM [31], Mass Tensor Model [32], finite element model (FEM) [27], and FEM with realistic tissue sliding effects [17]. On the other hand, free and open-source software has also been incorporated into studies of hard and soft tissue movement [4, 33, 34].

OOB is an add-on to the Blender 3D modeling suite which has been developed for teaching and carrying out digital planning of orthognathic surgery. The add-on consists of a set of sequential commands that have been organized and programmed to facilitate orthognathic surgery planning, providing the specialist not only with the solutions found natively in Blender but also with the ability to communicate with external third-party software to expand its potential. It was developed under a free and open-source license but can work seamlessly with closed and proprietary tools such as photogrammetry software and intraoral scanners [33]. OOB uses the mass spring mathematical deformation method (MSM), which employs a surface-based calculation system as its soft-body deformation model [Dalai Felinto, Blender Developer; personal communication, 7 Feb 2020] [https://docs. blender.org/manual/en/latest/animation/index.html].

The MSM assumes discretization of the deformable object into $n$ mass points and a set of connections between each of these points. To do so, the model starts from a tetrahedral discretization of the volume, assigns a mass point to each node in the mesh, and defines a linear spring for each mesh edge [35]. The reader will find mathematical formulas and models elsewhere [36, 37].
The objective of this study is to assess whether virtual simulation of the soft tissue outcomes of class II bimaxillary surgeries on a tissue mesh generated from 3D reconstruction of preoperative computed tomography scans of the face (M1) would differ significantly from the actual tissue repositioning obtained in the late postoperative period (beyond 6 months after surgery), as reflected on a mesh reconstructed from postoperative scans (M2), considering an error of up to $2 \mathrm{~mm}$ as acceptable for orthognathic surgery in the literature. Secondarily, we sought to validate the accuracy of soft tissue simulation for virtual planning of orthognathic surgery in the OOB free software suite.

\section{Material and methods}

\section{Ethical aspects}

The study protocol was submitted to and approved by the Instituto de Gestão Estratégica de Saúde do Distrito Federal (IGESDF) Research Ethics Committee (CAAE:12203819.8.0000.8153) with opinion number 3.732.163, after verification of compliance with ethical requirements and review of the risks and benefits of study participation. All participants provided written informed consent.

\section{Experiment design and sample selection}

In the last 6 years, 104 patients (aged 20 to 60 years) underwent bimaxillary orthognathic surgery aided by virtual planning to correct dentoskeletal deformities.

The present study included 16 clinically healthy patients, all classified as Angle class II, in whom control CT scans had been obtained at an interval of 6 to 72 months after surgery. All cases had undergone prior orthodontic preparation with a view to orthognathic surgery, and alar cinch sutures and upper lip V-Y closure were performed in all cases. Patients with syndromic dentofacial deformities, asymmetries, or a postoperative follow-up of less than 6 months were excluded (Fig. 1).

A flow diagram of sample selection is given in Fig. 2.

\section{Experimental study}

\section{Data collection}

The 16 selected patients underwent orthognathic surgery with bimaxillary advancement to correct class II dentoskeletal deformities. Patient selection, age, ethnicity, deformity, type of bimaxillary surgery, and the amount of movement performed are described in Table 1. Cases 7, 14, and 15 had no chin surgery. Case 4 had chin retrusion surgery. Alar cinch sutures and upper lip V-Y closure were performed in all 16 cases. 
Fig. 1 Study algorithm

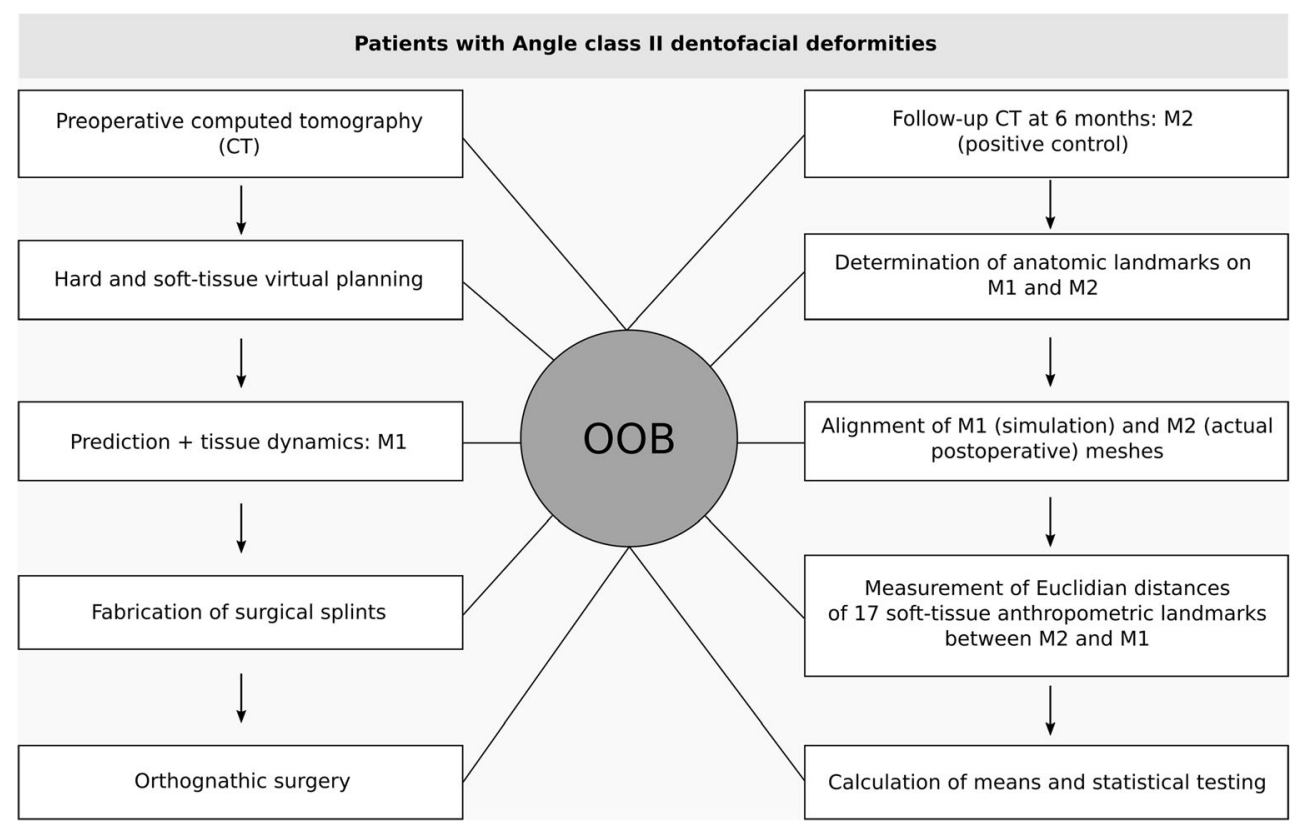

Moreover, in all cases, helical CT scans were obtained at baseline for surgical planning and postoperatively (at least 6 months after surgical intervention) for comparison. CT scans were performed with patients in the supine position, with facial muscles relaxed and a bite registration wax sheet interposed between the teeth, so as to avoid contact between the mandibular and maxillary arches (centric relation). The wax sheet was cut close to the teeth to avoid contact with the lips and cheeks. The CT scans were used to generate two

\section{Recruitment}

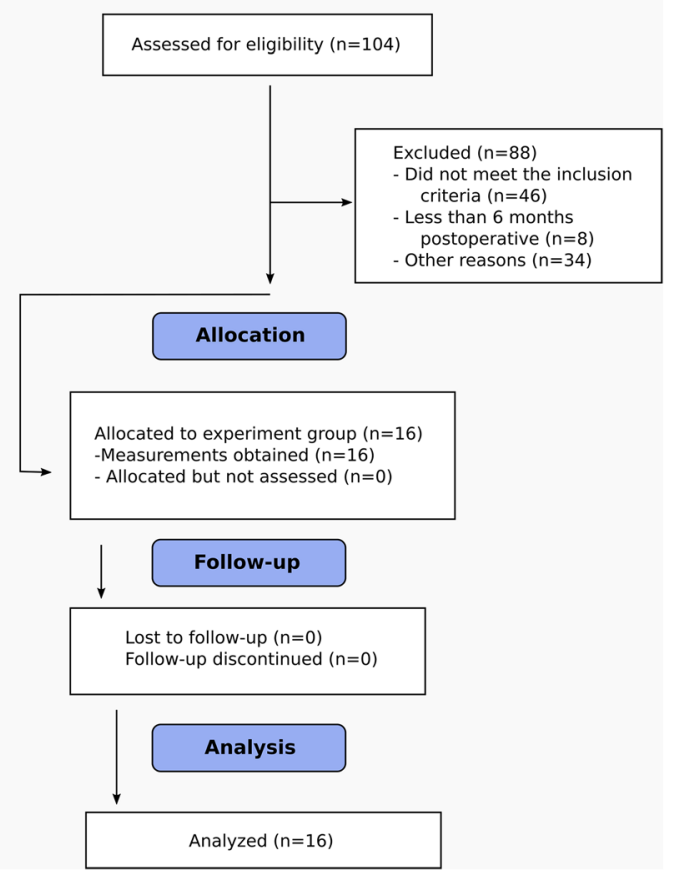

Fig. 2 Flow diagram of patient selection and analysis meshes (M1 and M2, respectively). The M1 mesh was obtained from the preoperative helical CT image. Using a mathematical algorithm, a 3D reconstruction of the skeletal and soft tissues of the face prior to surgery was generated. Using the dynamics of the bone and soft tissue meshes, a 3D simulation of the face was obtained, and 17 anatomic landmarks were incorporated into the soft tissue mesh, as described by Kim et al. [4]. The M2 mesh was constructed from the postoperative CT scan, obtained 6 to 72 months after the surgery, with the final outcome of the bone and soft tissues to serve as a positive control (patient as own control), with measurements compared to the preoperative landmarks (time point 0 ). Thus, the positions of the same 17 anatomic landmarks were determined in the M2 mesh.

\section{Alignment of CT scans}

To compare the anthropometric landmarks on the simulation mesh and the actual postoperative mesh, the CT meshes first need to be aligned. This alignment was performed on the basis of structures that did not change after surgery. The skull base, the bones of the nose, the frontal bone, and the zygomatic arches are stable structures and thus served as a reference for alignment because they do not undergo deformation from baseline in the postoperative period [13]. Because the soft tissue mesh is parented to the bone mesh, the soft tissues of the maxillary and mandibular regions are altered by a deformation algorithm. Blender employs the mass spring system mathematical deformation method, which applies a surfacebased calculation system as its soft-body deformation model [Dalai Felinto, Blender Developer; personal communication, 7 Feb 2020] [https://docs.blender.org/manual/en/latest/ animation/index.html]. 
Table 1 Patients characteristics, type of surgery, and amount of movement

\begin{tabular}{|c|c|c|c|c|c|c|}
\hline Patient & Age & Sex & Ethnicity & Deformity & Surgery & $\begin{array}{l}\text { Amount of } \\
\text { movement }\end{array}$ \\
\hline 1 & 29 & $\mathrm{~F}$ & Caucasian & $\begin{array}{l}\text { Class II bimaxillary } \\
\text { deficiency }\end{array}$ & $\begin{array}{l}\text { Max adv } \\
\text { Mand adv } \\
\text { Chin adv }\end{array}$ & $\begin{array}{l}4 \mathrm{~mm} \\
12 \mathrm{~mm} \\
6 \mathrm{~mm}\end{array}$ \\
\hline 2 & 27 & $\mathrm{~F}$ & Caucasian & $\begin{array}{l}\text { Class II bimaxillary } \\
\text { deficiency }\end{array}$ & $\begin{array}{l}\text { Max adv } \\
\text { Mand adv } \\
\text { Chin adv }\end{array}$ & $\begin{array}{l}7 \mathrm{~mm} \\
12 \mathrm{~mm} \\
8 \mathrm{~mm}\end{array}$ \\
\hline 3 & 48 & F & $\begin{array}{l}\text { African } \\
\text { American }\end{array}$ & $\begin{array}{l}\text { Class II bimaxillary } \\
\text { deficiency }\end{array}$ & $\begin{array}{l}\text { Max adv } \\
\text { Mand adv } \\
\text { Chin adv }\end{array}$ & $\begin{array}{l}6 \mathrm{~mm} \\
13 \mathrm{~mm} \\
6 \mathrm{~mm}\end{array}$ \\
\hline 4 & 27 & M & Caucasian & $\begin{array}{l}\text { Class II bimaxillary } \\
\text { deficiency } \\
\text { Chin protrusion }\end{array}$ & $\begin{array}{l}\text { Max adv } \\
\text { Mand adv } \\
\text { Chin retrusion }\end{array}$ & $\begin{array}{l}7 \mathrm{~mm} \\
13 \mathrm{~mm} \\
5 \mathrm{~mm}\end{array}$ \\
\hline 5 & 43 & $\mathrm{~F}$ & Caucasian & $\begin{array}{l}\text { Class II bimaxillary } \\
\text { deficiency }\end{array}$ & $\begin{array}{l}\text { Max adv } \\
\text { Mand adv } \\
\text { Chin adv }\end{array}$ & $\begin{array}{l}5 \mathrm{~mm} \\
8 \mathrm{~mm} \\
6 \mathrm{~mm}\end{array}$ \\
\hline 6 & 60 & F & Caucasian & $\begin{array}{l}\text { Class II bimaxillary } \\
\text { deficiency }\end{array}$ & $\begin{array}{l}\text { Max adv } \\
\text { Mand adv } \\
\text { Chin adv }\end{array}$ & $\begin{array}{l}7 \mathrm{~mm} \\
11 \mathrm{~mm} \\
6 \mathrm{~mm}\end{array}$ \\
\hline 7 & 50 & M & Caucasian & $\begin{array}{l}\text { Class II bimaxillary } \\
\text { deficiency }\end{array}$ & $\begin{array}{l}\text { Max adv } \\
\text { Mand adv }\end{array}$ & $\begin{array}{l}7 \mathrm{~mm} \\
9 \mathrm{~mm}\end{array}$ \\
\hline 8 & 48 & M & Caucasian & $\begin{array}{l}\text { Class II bimaxillary } \\
\text { deficiency }\end{array}$ & $\begin{array}{l}\text { Max adv } \\
\text { Mand adv } \\
\text { Chin adv }\end{array}$ & $\begin{array}{l}7 \mathrm{~mm} \\
10 \mathrm{~mm} \\
2 \mathrm{~mm}\end{array}$ \\
\hline 9 & 25 & $\mathrm{~F}$ & Caucasian & $\begin{array}{l}\text { Class II bimaxillary } \\
\text { deficiency }\end{array}$ & $\begin{array}{l}\text { Max adv } \\
\text { Mand adv } \\
\text { Chin adv }\end{array}$ & $\begin{array}{l}7 \mathrm{~mm} \\
5 \mathrm{~mm} \\
8 \mathrm{~mm}\end{array}$ \\
\hline 10 & 20 & F & Caucasian & $\begin{array}{l}\text { Class II bimaxillary } \\
\text { deficiency }\end{array}$ & $\begin{array}{l}\text { Max adv } \\
\text { Mand adv } \\
\text { Chin adv }\end{array}$ & $\begin{array}{l}5 \mathrm{~mm} \\
6 \mathrm{~mm} \\
6 \mathrm{~mm}\end{array}$ \\
\hline 11 & 35 & M & Caucasian & $\begin{array}{l}\text { Class II bimaxillary } \\
\text { deficiency }\end{array}$ & $\begin{array}{l}\text { Max adv } \\
\text { Mand adv } \\
\text { Chin adv }\end{array}$ & $\begin{array}{l}5 \mathrm{~mm} \\
11 \mathrm{~mm} \\
6 \mathrm{~mm}\end{array}$ \\
\hline 12 & 28 & F & Caucasian & $\begin{array}{l}\text { Class II bimaxillary } \\
\text { deficiency }\end{array}$ & $\begin{array}{l}\text { Max adv } \\
\text { Mand adv } \\
\text { Chin adv }\end{array}$ & $\begin{array}{l}5 \mathrm{~mm} \\
11 \mathrm{~mm} \\
2 \mathrm{~mm}\end{array}$ \\
\hline 13 & 29 & F & Caucasian & $\begin{array}{l}\text { Class II bimaxillary } \\
\text { deficiency }\end{array}$ & $\begin{array}{l}\text { Max adv } \\
\text { Mand adv } \\
\text { Chin adv }\end{array}$ & $\begin{array}{l}7 \mathrm{~mm} \\
17 \mathrm{~mm} \\
2 \mathrm{~mm}\end{array}$ \\
\hline 14 & 48 & F & Caucasian & $\begin{array}{l}\text { Class II bimaxillary } \\
\text { deficiency }\end{array}$ & $\begin{array}{l}\text { Max adv } \\
\text { Mand adv }\end{array}$ & $\begin{array}{l}8 \mathrm{~mm} \\
10 \mathrm{~mm}\end{array}$ \\
\hline 15 & 35 & $\mathrm{~F}$ & Caucasian & $\begin{array}{l}\text { Class II bimaxillary } \\
\text { deficiency }\end{array}$ & $\begin{array}{l}\text { Max adv } \\
\text { Mand adv }\end{array}$ & $\begin{array}{l}7 \mathrm{~mm} \\
10 \mathrm{~mm}\end{array}$ \\
\hline 16 & 25 & M & Caucasian & $\begin{array}{l}\text { Class II bimaxillary } \\
\text { deficiency }\end{array}$ & $\begin{array}{l}\text { Max adv } \\
\text { Mand adv } \\
\text { Chin adv }\end{array}$ & $\begin{array}{l}5 \mathrm{~mm} \\
6 \mathrm{~mm} \\
8 \mathrm{~mm}\end{array}$ \\
\hline
\end{tabular}

$F$ feminine, $M$ masculine, Max maxilla, Mand mandible, $A d v$ advancement 
The quantitative parameters (defined for each region of the face) used for simulation of soft tissue movements based on the influence of underlying skeletal tissue dynamics were established in a previous study (in press). These different simulation parameters for each region of the mesh (e.g., maxilla, mandible, chin) are applied in Blender using the Weight Paint tool [https://docs.blender.org/manual/en/latest/sculpt_paint/ weight_paint/index.html].

\section{Definition of anthropometric landmarks}

The 17 anthropometric landmarks used in this study were defined as per the previous work of Kim et al. [4] (Table 2 and Fig.3). In the sum of selected sample $(n=16), 272$ points in M1 meshes and 272 points in M2 meshes were compared. After alignment of the cranial structures, the predetermined anatomic landmarks in M1 and M2 were measured three-

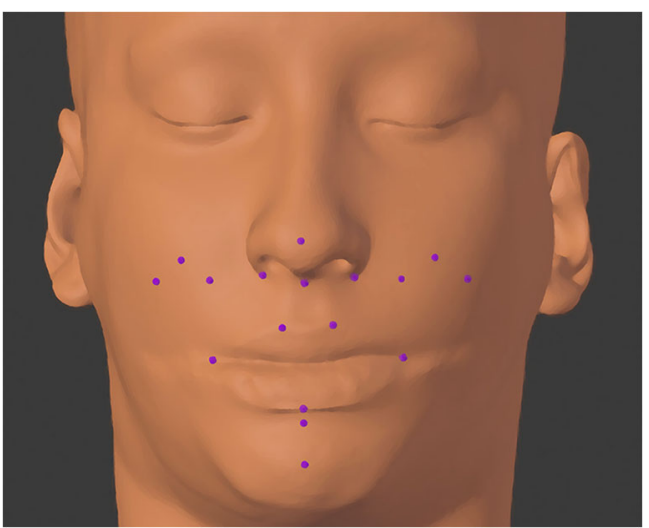

Fig. 3 3D reconstruction of facial soft tissues. Image captured from OrtogOnBlender. Anthropometric landmarks superimposed on 3D facial soft tissue mesh

dimensionally by the Euclidean method, considering each point of the M2 mesh as the initial reference or zero point.
Table 2 Definition of soft tissue landmarks [4]

\begin{tabular}{|c|c|}
\hline $\begin{array}{l}\text { Soft tissue anatomic } \\
\text { landmarks }\end{array}$ & Definition \\
\hline \multicolumn{2}{|l|}{ Lip measurements } \\
\hline Rt.Cu (right Cupid's bow) & $\begin{array}{l}\text { Most prominent point of the vermilion border of the right Cupid's bow of the } \\
\text { upper lip }\end{array}$ \\
\hline Lt.Cu (left Cupid's bow) & $\begin{array}{l}\text { Most prominent point of the vermilion border of the left Cupid's bow of the } \\
\text { upper lip }\end{array}$ \\
\hline Rt.Ch (right cheilion) & Most lateral extent of the outline of the lip on the right side \\
\hline Lt.Ch (left cheilion) & Most lateral extent of the outline of the lip on the left side \\
\hline LL (lower lip) & Most prominent point of vermilion border of Cupid's bow of lower lip \\
\hline \multicolumn{2}{|l|}{ Cheek measurements } \\
\hline Rt.Ck (right cheek) & Most prominent point of the cheek on the right side \\
\hline Lt.Ck (left cheek) & Most prominent point of the cheek on the left side \\
\hline $\begin{array}{l}\text { Rt.Exo-Al (right } \\
\text { exocanthus-alar base) }\end{array}$ & Intersection point of the right exocanthus and right alar base \\
\hline $\begin{array}{l}\text { Lt.Exo-Al (left } \\
\text { exocanthus-alar base) }\end{array}$ & Intersection point of the left exocanthus and left alar base \\
\hline $\begin{array}{l}\text { Rt.Ch-Al (right } \\
\text { cheilion-alar base) }\end{array}$ & $\begin{array}{l}\text { Intersection point formed by a line parallel to the midsagittal plane passing } \\
\text { through the right cheilion and a line perpendicular to the midsagittal plane } \\
\text { passing through the right alar base }\end{array}$ \\
\hline $\begin{array}{l}\text { Lt.Ch-Al (left cheilion-alar } \\
\text { base) }\end{array}$ & $\begin{array}{l}\text { Intersection point formed by a line parallel to the midsagittal plane passing } \\
\text { through the left cheilion and a line perpendicular to the midsagittal plane } \\
\text { passing through the left alar base }\end{array}$ \\
\hline \multicolumn{2}{|l|}{ Chin measurements } \\
\hline Pog' (soft tissue pogonion) & Most anterior point of chin \\
\hline $\mathrm{B}^{\prime}$ (soft tissue B point) & Most concave point on the curve between LL and Pog' \\
\hline \multicolumn{2}{|l|}{ Nasal measurements } \\
\hline Pn (pronasale) & Most anterior point of nose \\
\hline Rt.Al (right alar base) & $\begin{array}{l}\text { Most lateral point in curved baseline of alar on right side, indicating the facial } \\
\text { insertion of the nasal wing base }\end{array}$ \\
\hline Lt.Al (left alar base) & $\begin{array}{l}\text { Most lateral point in curved baseline of alar on left side, indicating the facial } \\
\text { insertion of the nasal wing base }\end{array}$ \\
\hline Sn (subnasale) & Point at which the columella merges with the upper lip in the sagittal plane \\
\hline
\end{tabular}




\section{Comparative measurement of landmarks on M1 and M2}

The CompareOnBlender tool (an OOB add-on) was used to perform absolute 3D measurement between the landmarks of interest on the M1 and M2 meshes (paired-point matching) [14]). This calculation was performed linearly using the following formula: $d_{\mathrm{AB}}=\sqrt{ }$ $\left(\mathrm{X}_{\mathrm{B}}-\mathrm{X}_{\mathrm{A}}\right)^{2}+\left(\mathrm{Y}_{\mathrm{B}}-\mathrm{Y}_{\mathrm{A}}\right)^{2}+\left(\mathrm{Z}_{\mathrm{B}}-\mathrm{Z}_{\mathrm{A}}\right)^{2}$, where $B$, point of interest on $\mathrm{M} 2 ; A$, point of interest on $\mathrm{M} 1 ; d_{\mathrm{AB}}$, distance between point $A$ and point $B ; X$, coordinate of the point of interest on the $x$-axis; $Y$, coordinate of the point of interest on the $y$-axis; and $Z$, coordinate of the point of interest on the $z$-axis (Fig. 4 and Fig. 5).

As in previous studies, the accuracy of prediction in each of the Cartesian coordinates $(x, y, z)$ was not stratified in this study [3].

The yellow facial contour in image 1 (Fig. 6) represents the preoperative CT mesh, while the orange outline represents the postoperative facial contour. Image 2 again shows the M1 (surgical simulation) mesh represented in yellow, while the outline in orange represents the M2 (actual postoperative) mesh.

\section{Color distance map}

A $3 \mathrm{D}$ color map is a graphical representation of the differences in distance between two overlapping 3D images [35]. In the field of oral and maxillofacial surgery,

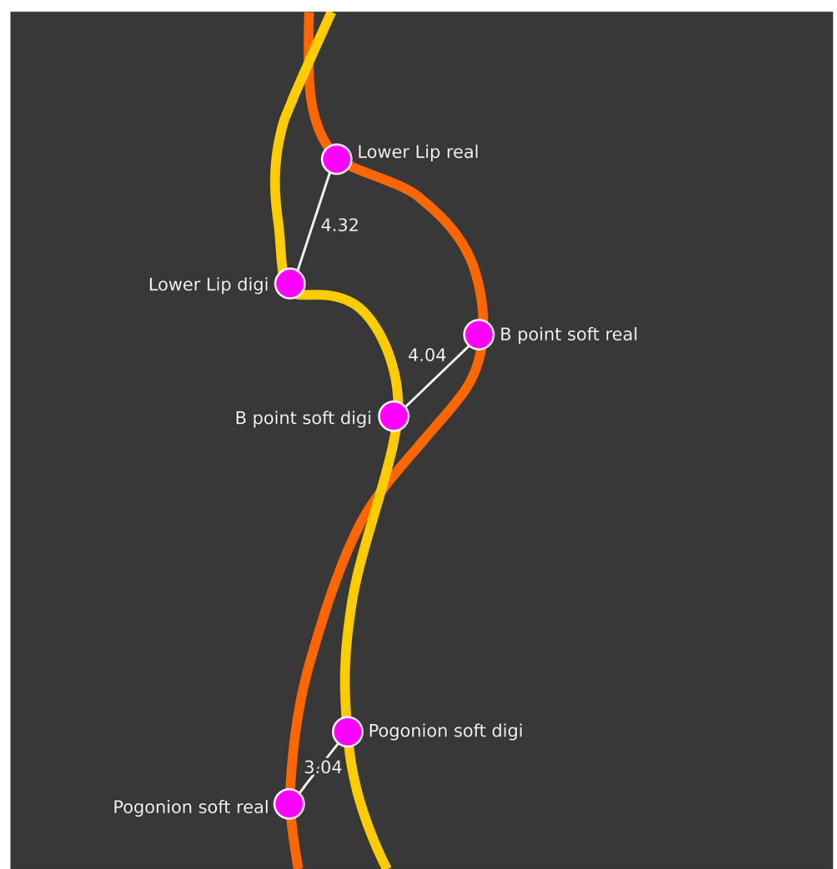

Fig. 4 Sagittal section of M1 and M2 meshes (OOB, solid mode). Measurement of the distances between $\mathrm{M} 2$ and M1, sagittal view: linear measurement represented by the expression $\left[d_{\mathrm{AB}}=\sqrt{ }\left(\mathrm{X}_{\mathrm{B}}-\mathrm{X}_{\mathrm{A}}\right)^{2}+\left(\mathrm{Y}_{\mathrm{B}}-\right.\right.$ $\left.\left.\mathrm{Y}_{\mathrm{A}}\right)^{2}+\left(\mathrm{Z}_{\mathrm{B}}-\mathrm{Z}_{\mathrm{A}}\right)^{2}\right]$. Digi = digital simulation vs. actual position

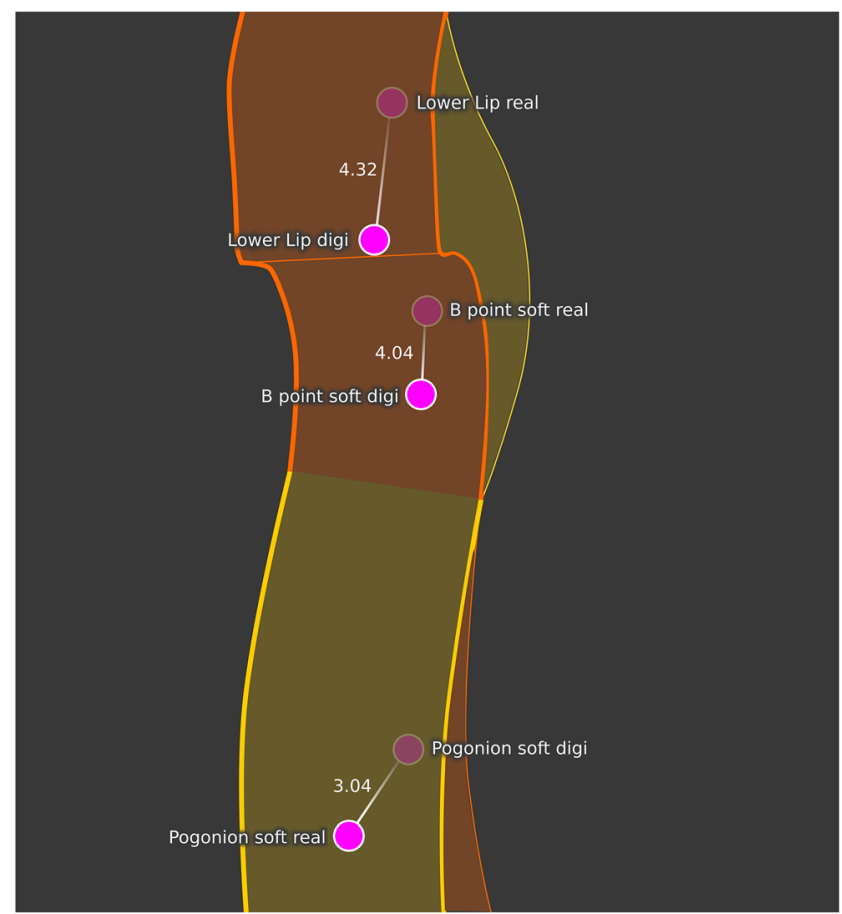

Fig. 5 Sagittal section of M1 and M2 meshes (OOB, wireframe mode). Three-dimensional fronto-lateral section in wireframe mode, showing comparative measurement of landmarks on the M1 mesh (simulated) and M2 mesh (actual)

they can be used for preoperative evaluation, surgical planning, and evaluation of surgical outcomes [18, 22, 23]. They facilitate objective assessment of structures and improve visual understanding and communication with patients. Three-dimensional (3D) color maps are particularly useful for analyzing data acquired by laser scanning, stereophotogrammetry, photogrammetry, or CT scans [33, 35]. The CloudCompare program (free and open-source software, http://www.daneilgm.net) has been used for quantitative assessments in orthognathic surgery [38, 39]. CloudCompare is an open-source program for processing 3D point clouds, triangular meshes, and other images. In the present study, CloudCompare will be used to decompose the $3 \mathrm{D}$ meshes into a number $(n)$ of points (i.e., a point cloud) and then compare deviations between the points of the M1 mesh and the positive-control M2 mesh.

\section{Study error}

The decision to use a model based on marking anthropometric landmarks of interest [4] was due to its greater reproducibility and lower margin of error. The markings were repeated by the same operator after a 2-week interval, and the difference between point locations was found to be less than $0.5 \mathrm{~mm}$. 
Fig. 6 Alignment and superimposition of 3D mesh reconstruction of soft tissue $\mathrm{CT}$ scans obtained preoperatively and postoperatively using OOB. a Alignment of CT meshes. Yellow contour represents the preoperative scan; orange represents the postoperative scan. b Alignment of meshes M1 (simulation, yellow) and M2 (postoperative, orange)
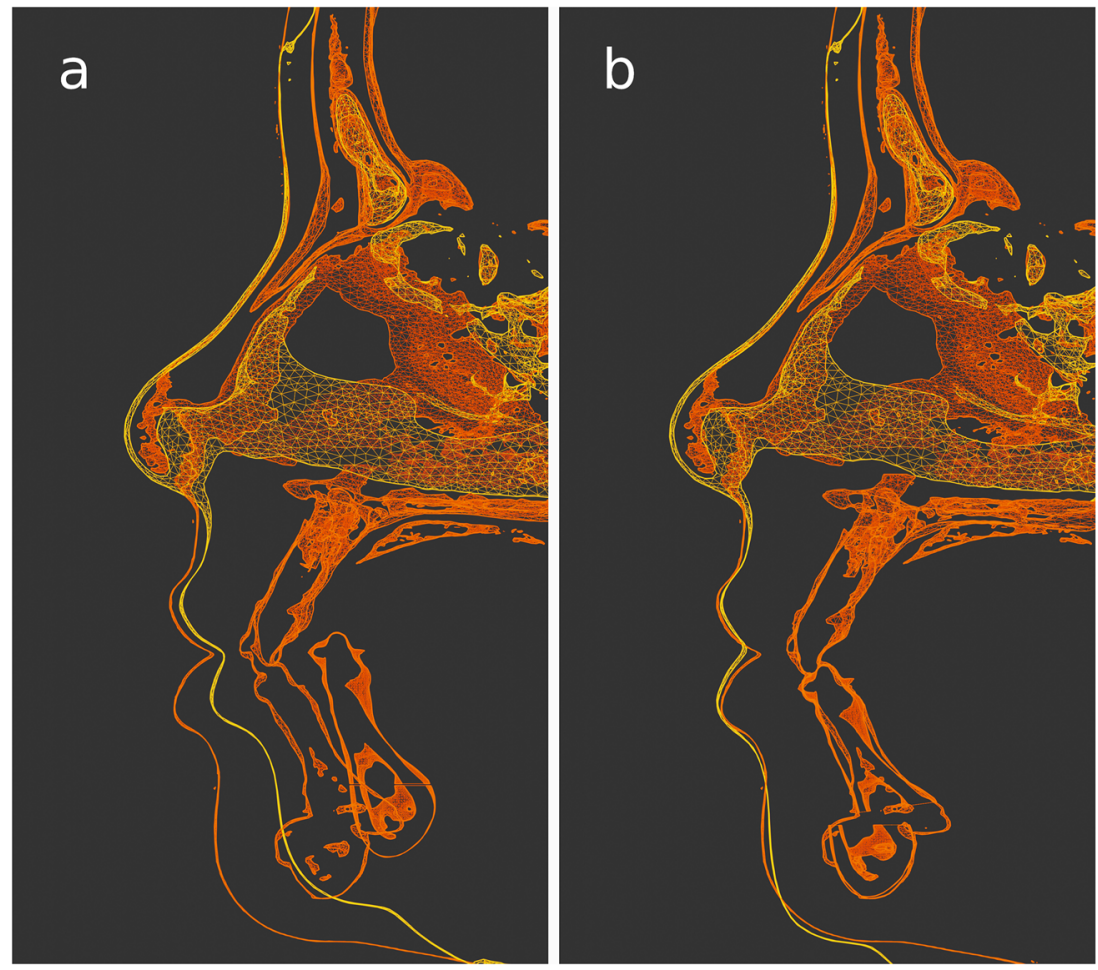

\section{Statistical analysis}

\section{Statistical tests employed}

Statistical analyses will be performed by calculation of confidence intervals and by the single-mean $t$ test, which aims to compare the mean deviations between the variables (real versus simulated) with the hypothetical acceptable reference error reported in the literature $(2 \mathrm{~mm})$. Analysis will first focus on the mean deviation, lower and upper limits of the $95 \%$ confidence interval (i.e., 95\% confidence that the interval between the lower limit and the upper limit contains the true value of the sample mean), maximum, minimum, and standard deviation. Next, it will ascertain whether the aforementioned means differ statistically from $2 \mathrm{~mm}$, aiming to verify whether any of the variables exhibited a statistically significant deviation greater than $2 \mathrm{~mm}$. The degrees of freedom (DF) method will be used, which estimates the number of independent categories in a given statistical test, obtained by the formula $n-1$, where $n$ is the number of elements in the sample. The single-mean $t$ test corresponds to the $t$ statistic, an abstract number (the higher this number, the more divergent the averages compared), and $p$ is the level of statistical probability. All statistical procedures were performed in the Statistica 8.0 software suite (TIBCO Software Inc., Palo Alto, CA, USA).

\section{Decision rule}

The significance level was set at 5\% for all tests. Differences between parameters were thus considered significant when the $p$ value was less than $0.05(p<0.05)$.

\section{Results}

Initial screening resulted in assessment for eligibility of 104 patients. Eighty-eight of these $(n=88)$ were excluded from the study: 46 did not meet the inclusion criteria, 8 had undergone surgery less than 6 months before, and 34 were excluded for other reasons. Sixteen patients were ultimately allocated to the experiments $(n=16)$.

Table 3 shows the descriptive statistics for deviation (mean, lower limit with $95 \%$ confidence interval, upper limit with 95\% confidence interval, minimum, maximum, standard deviation). The first column refers to the 17 anatomic landmarks selected on the face in the 16 patients allocated to the experiment group. Sim represents each anatomic landmark on the simulated soft tissue mesh (M1), while Real represents the actual position of the same landmark on the postoperative soft tissue mesh (M2), represented with a reference value of $0 \mathrm{~mm}$ (zero). Mean refers to the average deviation in $\mathrm{mm}$ for each anatomic landmark (M2 to M1). 95\% CI LL refers to the lower limit of the $95 \%$ confidence interval, $95 \%$ CI UL refers 
Table 3 Descriptive deviation statistics for each variable

\begin{tabular}{|c|c|c|c|c|c|c|}
\hline $\begin{array}{l}\text { Anatomic } \\
\text { landmarks }\end{array}$ & Mean & $\begin{array}{l}95 \% \text { CI } \\
\text { LL }\end{array}$ & $\begin{array}{l}95 \% \text { CI } \\
\text { UL }\end{array}$ & Minimum & Maximum & $\begin{array}{l}\text { Standard } \\
\text { deviation }\end{array}$ \\
\hline PnSim & -0.78375 & -1.65887 & 0.091374 & -3.94000 & 1.900000 & 1.642307 \\
\hline PnReal & 0.00000 & & & 0.00000 & 0.000000 & 0.000000 \\
\hline Rt.Exo-AlSim & -1.50125 & -2.72045 & -0.282050 & -5.99000 & 3.030000 & 2.288021 \\
\hline Rt.Exo-AlReal & 0.00000 & & & 0.00000 & 0.000000 & 0.000000 \\
\hline Rt.CkSim & -1.23687 & -2.00992 & -0.463835 & -3.51000 & 1.050000 & 1.450732 \\
\hline Rt.CkReal & 0.00000 & & & 0.00000 & 0.000000 & 0.000000 \\
\hline Rt.AlSim & -0.55125 & -1.53668 & 0.434177 & -2.91000 & 2.420000 & 1.849309 \\
\hline Rt.Al Real & 0.00000 & & & 0.00000 & 0.000000 & 0.000000 \\
\hline SnSim & 0.57938 & -0.40470 & 1.563450 & -2.39000 & 3.510000 & 1.846772 \\
\hline SnReal & 0.00000 & & & 0.00000 & 0.000000 & 0.000000 \\
\hline Lt.AlSim & -0.65187 & -1.61255 & 0.308804 & -2.87000 & 3.110000 & 1.802865 \\
\hline Lt.AlReal & 0.00000 & & & 0.00000 & 0.000000 & 0.000000 \\
\hline Lt.CkSim & -0.63563 & -1.53394 & 0.262689 & -4.00000 & 1.840000 & 1.685827 \\
\hline Lt.CkReal & 0.00000 & & & 0.00000 & 0.000000 & 0.000000 \\
\hline Lt.Exo-AlSim & -1.21125 & -2.02813 & -0.394367 & -3.84000 & 1.650000 & 1.533010 \\
\hline Lt.Exo-AlReal & 0.00000 & & & 0.00000 & 0.000000 & 0.000000 \\
\hline Rt.Ch-AlSim & -1.69687 & -2.70029 & -0.693455 & -4.05000 & 2.170000 & 1.883075 \\
\hline Rt.Ch-AlReal & 0.00000 & & & 0.00000 & 0.000000 & 0.000000 \\
\hline Rt.CuSim & -0.96125 & -2.06051 & 0.138014 & -3.84000 & 3.530000 & 2.062942 \\
\hline Rt.CuReal & 0.00000 & & & 0.00000 & 0.000000 & 0.000000 \\
\hline Lt.CuSim & -1.34750 & -2.35978 & -0.335216 & -4.09000 & 3.540000 & 1.899711 \\
\hline Lt.CuReal & 0.00000 & & & 0.00000 & 0.000000 & 0.000000 \\
\hline Lt.Ch-AlSim & -1.23937 & -2.11534 & -0.363407 & -4.10000 & 1.820000 & 1.643892 \\
\hline Lt.Ch-AlReal & 0.00000 & & & 0.00000 & 0.000000 & 0.000000 \\
\hline Rt.ChSim & 1.61563 & -0.19378 & 3.425032 & -3.49000 & 5.560000 & 3.395636 \\
\hline Rt.ChReal & 0.00000 & & & 0.00000 & 0.000000 & 0.000000 \\
\hline Lt.ChSim & 1.69125 & -0.01020 & 3.392701 & -3.55000 & 6.180000 & 3.193040 \\
\hline Lt.ChReal & 0.00000 & & & 0.00000 & 0.000000 & 0.000000 \\
\hline LLSim & 0.59562 & -0.78014 & 1.971387 & -3.14000 & 4.320000 & 2.581834 \\
\hline LLReal & 0.00000 & & & 0.00000 & 0.000000 & 0.000000 \\
\hline B'Sim & 0.75750 & -1.12315 & 2.638150 & -5.62000 & 6.310000 & 3.529335 \\
\hline B'Real & 0.00000 & & & 0.00000 & 0.000000 & 0.000000 \\
\hline Pog'Sim & -1.29312 & -2.41790 & -0.168351 & -4.14000 & 3.160000 & 2.110816 \\
\hline Pog'Real & 0.00000 & & & 0.00000 & 0.000000 & 0.000000 \\
\hline
\end{tabular}

to the upper limit of the $95 \%$ confidence interval, minimum and maximum refer to the lowest and highest values of the variables within the sample (thus representing the data interval for each anatomic landmark), and standard deviation refers to the dispersion of data in relation to the mean for each anatomic landmark in the M1 mesh in the selected sample.

Table 4 shows comparison of mean deviations to the 2$\mathrm{mm}$ reference value (mean, standard deviation, reference constant, $t$ statistic, DF, and $p$ ). Again, the first column refers to the 17 anatomic landmarks selected on the face in the 16 patients allocated to the experiment group. Sim represents each anatomic landmark on the simulated soft tissue mesh (M1), while Real represents the actual position of the same landmark on the postoperative soft tissue mesh (M2), represented with a reference value of $0 \mathrm{~mm}$ (zero). Mean refers to the average deviation in $\mathrm{mm}$ for each anatomic landmark (M2 to M1). Reference constant refers to the hypothetical acceptable reference error of $2 \mathrm{~mm}$, as reported in the scientific literature. $t$ is the $t$ statistic for the single-mean $t$ test, which compares the mean deviations of the variables to the $2-\mathrm{mm}$ reference constant. DF refers to degrees of freedom, i.e., the number of independent categories in the statistical test, obtained with the formula $n-1$, where $n$ is the number of elements 
Table 4 Comparison of standard deviations to the $2 \mathrm{~mm}$ reference constant value

\begin{tabular}{|c|c|c|c|c|c|c|}
\hline $\begin{array}{l}\text { Anatomic } \\
\text { landmarks }\end{array}$ & Mean & $\begin{array}{l}\text { Standard } \\
\text { deviation }\end{array}$ & $\begin{array}{l}\text { Reference } \\
\text { constant }\end{array}$ & $t$ & $\begin{array}{l}\text { Degrees of } \\
\text { freedom }\end{array}$ & $p$ \\
\hline PnSim & -0.78375 & 1.642307 & 2.000000 & -6.78010 & 15 & 0.000006 \\
\hline PnReal & 0.00000 & & 2.000000 & & 15 & \\
\hline Rt.Exo-AlSim & -1.50125 & 2.288021 & 2.000000 & -6.12101 & 15 & 0.000020 \\
\hline Rt.Exo-AlReal & 0,00000 & & 2.000000 & & 15 & \\
\hline Rt.CkSim & -1.23687 & 1.450732 & 2.000000 & -8.92481 & 15 & 0.000000 \\
\hline Rt.CkReal & 0.00000 & & 2.000000 & & 15 & \\
\hline Rt.AlSim & -0.55125 & 1.849309 & 2.000000 & -5.51828 & 15 & 0.000059 \\
\hline Rt.Al Real & 0.00000 & & 2.000000 & & 15 & \\
\hline SnSim & 0.57938 & 1.846772 & 2.000000 & -3.07699 & 15 & 0.007669 \\
\hline SnReal & 0.00000 & & 2.000000 & & 15 & \\
\hline Lt.AlSim & -0.65187 & 1.802865 & 2.000000 & -5.88369 & 15 & 0.000030 \\
\hline Lt.AlReal & 0.00000 & & 2.000000 & & 15 & \\
\hline Lt.CkSim & -0.63563 & 1.685827 & 2.000000 & -6.25361 & 15 & 0.000015 \\
\hline Lt.CkReal & 0.00000 & & 2.000000 & & 15 & \\
\hline Lt.Exo-AlSim & -1.21125 & 1.533010 & 2.000000 & -8.37894 & 15 & 0.000000 \\
\hline Lt.Exo-AlReal & 0.00000 & & 2.000000 & & 15 & \\
\hline Rt.Ch-AlSim & -1.69687 & 1.883075 & 2.000000 & -7.85285 & 15 & 0.000001 \\
\hline Rt.Ch-AlReal & 0.00000 & & 2.000000 & & 14 & \\
\hline Rt.CuSim & -0.96125 & 2.062942 & 2.000000 & -5.74180 & 15 & 0.000039 \\
\hline Rt.CuReal & 0.00000 & & 2.000000 & & 15 & \\
\hline Lt.CuSim & -134750 & 1.899711 & 2.000000 & -7.04844 & 15 & 0.000004 \\
\hline Lt.CuReal & 0,00000 & & 2.000000 & & 15 & \\
\hline Lt.Ch-AlSim & $-1.23,937$ & 1.643892 & 2.000000 & -7.88221 & 15 & 0.000001 \\
\hline Lt.Ch-AlReal & 0.00000 & & 2.000000 & & 15 & \\
\hline Rt.ChSim & 1.61563 & 3.395636 & 2.000000 & -0.45279 & 15 & 0.657182 \\
\hline Rt.ChReal & 0.00000 & & 2.000000 & & 15 & \\
\hline Lt.ChSim & 1.69125 & 3.193040 & 2.000000 & -0.38678 & 15 & 0.704352 \\
\hline Lt.ChReal & 0.00000 & & 2.000000 & & 15 & \\
\hline LLSim & 0.59562 & 2.581834 & 2.000000 & -2.17578 & 15 & 0.045969 \\
\hline LLReal & 0.00000 & & 2.000000 & & 15 & \\
\hline B'Sim & 0.75750 & 3.529335 & 2.000000 & -1.40820 & 15 & 0.179461 \\
\hline B'Real & 0.00000 & & 2.000000 & & 15 & \\
\hline
\end{tabular}

in the sample $(n=16)$. Standard deviation refers to the dispersion of data in relation to the mean for each anatomic landmark in the M1 mesh in the selected sample.

Figure 7 shows a Cartesian plane with a representation of the 17 selected facial anatomic landmarks (real vs. simulation) on the $x$-axis and the deviation in mm on the $y$-axis, where 0 represents the averages of the M2 meshes and the averages of the simulations are represented by positive and negative numeric values along the $y$-axis, depending on whether the simulated values obtained were short (negative) of the actual values obtained ( $70.58 \%$ of all points) or exceeded (positive) the actual values (29.41\% of all points), as compared to the Real M2 mesh ( $0 \mathrm{~mm})$. In addition, means, standard error, and $95 \%$ confidence intervals are reported.
The positive and negative mean values are Cartesian representations that express the position of the anthropometric landmarks on the M1 and M2 meshes. In other words, when the simulated (M1) points fell short of the actual surgical movement (M2), the variation was negative. When the simulated (M1) points were proud of the actual location of the landmarks after surgery (M2), the variation was positive.

As shown in Figs. 7, 12 landmarks on the M1 mesh (simulated) presented an average value short of their actual position on the M2 mesh (postoperative): Pn, Rt Exo-Al, Rt Ck, Rt Al, Lt Al, Lt Ck, Lt Exo-Al, Rt Ch-Al, Rt Cu, Lt Cu, Lt $\mathrm{Ch}-\mathrm{Al}$, and Pog. On the other hand, five landmarks on the M1 mesh were beyond their actual positions on the M2 mesh: Sn, Rt Ch, Lt Ch, LL, and B'. 
Fig. 7 Cartesian plane comprising facial anthropometric landmarks, deviation in $\mathrm{mm}$, means, standard error, and confidence interval (95\%). The black arrow shows the reference constant, which corresponds to the clinically acceptable error as described in the literature $(\leq 2 \mathrm{~mm})$

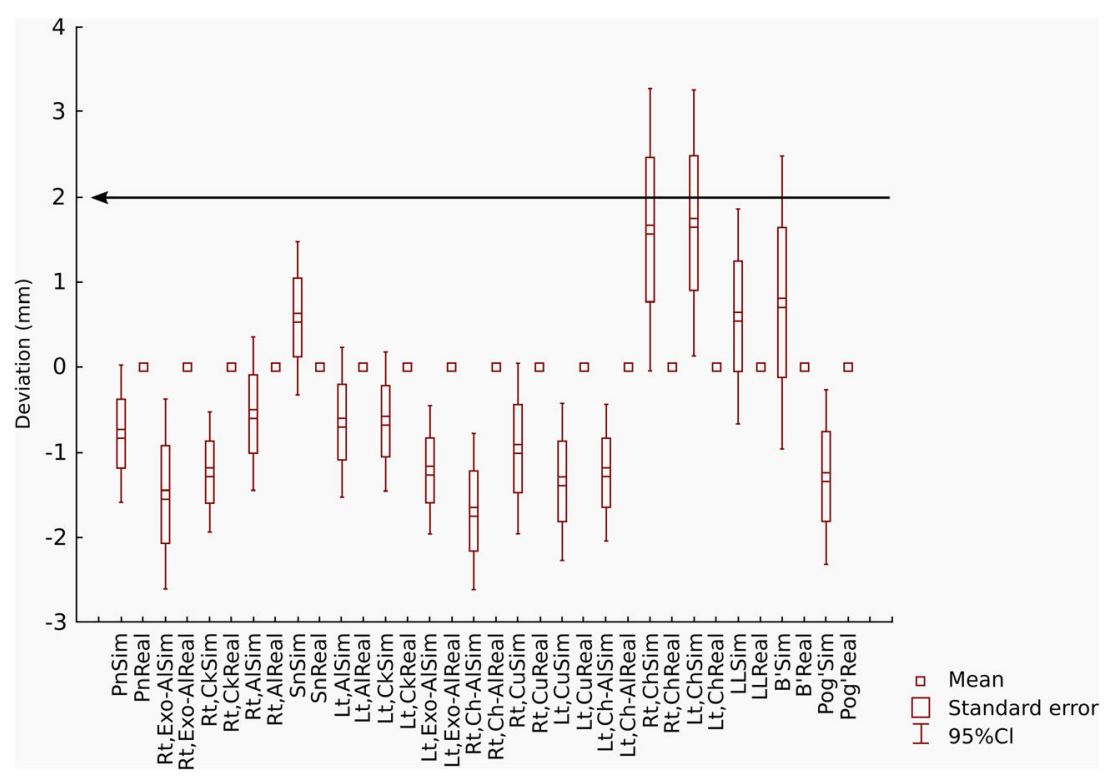

To obtain the overall mean of the landmarks, their absolute values were considered, because the objective was to obtain the difference between M2 and M1 regardless of whether it was below or beyond the M2 reference. Thus, the overall mean error for all facial landmarks selected for this study was $1.0793 \mathrm{~mm}$.

Figure 7 shows a black arrow indicating the reference constant, $2 \mathrm{~mm}$. Points located below this constant have a mean deviation of less than $2 \mathrm{~mm}$, with a statistically significant difference. No variable is located above the arrow on the graph, i.e., none showed a statistically significant deviation greater than $2 \mathrm{~mm}(+2 \mathrm{~mm}$ or $-2 \mathrm{~mm})$.

The points whose averages on M1 showed the greatest dispersion (discrepancy), i.e., those in which actual surgical movement (M2) was most different from the simulation, were Rt, ChSim $(p=0.657182), \mathrm{Lt}, \mathrm{ChSim}(p=0.704352)$, and B'Sim $(p=0.1779461)$.

Figure 8 depicts a frontal view of a color distance map with superimposition of the simulated soft tissue mesh (M1) and the actual postoperative soft tissue mesh (M2). The greenshaded areas represent those areas in which the overlap between the M1 and M2 meshes coincides. Asterisks (*) in the yellow region represent a slight overcorrection of the M1 mesh beyond the M2 mesh, while the black arrow pointing to a minute region of red shading represents a more substantial overcorrection of the M1 mesh beyond the M2 mesh. The vertical color bar shows the positive and negative distances (in $\mathrm{mm}$ ) between the M1 and M2 meshes, in addition to their intensity/concentration and dispersion in relation to the zero landmark (M2).

Figure 9 shows a facial frontal image of a color distance map with superimposition of the simulated soft tissue mesh (M1) and the actual postoperative soft tissue mesh (M2). The green-shaded areas represent those areas in which the overlap between the M1 and M2 meshes coincides. The blue regions (both cheeks and chin) represent undercorrection of the M1 mesh short of the M2 mesh, while the intense red shading on the lower lip represents overcorrection of the M1 mesh beyond the M2 mesh. The vertical color bar shows the positive and negative distances (in $\mathrm{mm}$ ) between the M1 and M2 meshes, in addition to their intensity/concentration and dispersion in relation to the zero landmark (M2).

\section{Discussion}

In this experimental study, OOB demonstrated accuracy in predicting facial soft tissue movements in $3 \mathrm{D}$ virtual planning of orthognathic surgery. OOB is an add-on software developed for teaching and carrying out digital planning of orthognathic surgery. It is based on Blender (Blender Foundation), a free, open-source software suite for 3D modeling, animation, texture mapping, compositing, rendering, and video editing [33, 38]. Computational deformation methods for simulation of soft tissue surgical outcomes on a face mesh described in the literature include the mass spring model [28, 30], Tetrahedral Mass Tensor Model (non-rigid TPS-RPM) [32], Tetrahedral Mass Spring Model [31], Mass Tensor Model [40], finite element model (FEM) [27], and FEM with slide effects [17, 34]. OOB uses the well-established mass spring system mathematical deformation method, which employs a surface-based calculation system as its soft-body deformation model [33]. However, no studies have demonstrated the accuracy of this software add-on. Previous studies of proprietary algorithms, including Morpheus 3D Facemaker® [41], Dolphin ${ }^{\circledR}$ [29], SurgiCase CMF® [18, 42], $3 \mathrm{dMDvultus} \AA[30]$, OrthoForecast ${ }^{\circledR}$ [43], and Sotirios ${ }^{\circledR}$ [44], have shown good precision in predicting soft tissue 


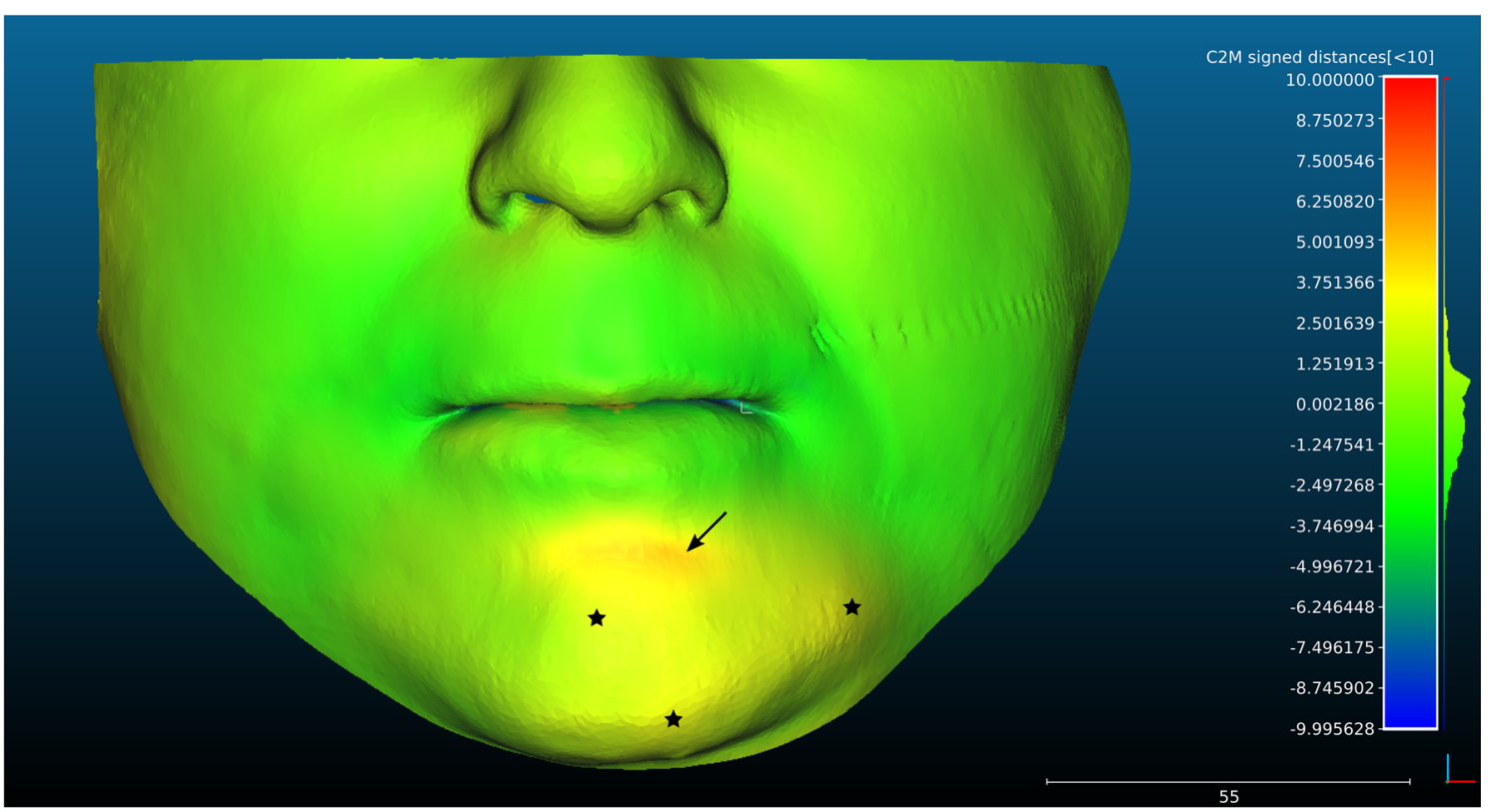

Fig. 8 Color distance map, prediction soft tissue mesh (M1) versus actual postoperative soft tissue mesh (M2)

changes after orthognathic surgery and sufficient accuracy for clinical use. Detailed information on soft tissue deformation methods is available elsewhere [17, 18, 27, 31, 36, 45].

In 2004, Mollemans et al. [31] compared a tetrahedral MSM method with an FEM method and obtained similar results between the two models in terms of the accuracy of soft tissue simulation. However, Mollemans et al. [37], in a later comparison of four models - linear finite element model (FEM), nonlinear finite element model (NFEM), mass spring model (MSM), and a new Mass Tensor Model (MTM) - stated that the MSM has the advantage of being simple and computationally efficient, while its main disadvantage is that the elastic behavior of the model is determined by the spring constant, which is an approximation and has no real biomechanical relevance However, in the present study using the OOB, the MSM model showed clinical relevance, considering that the mean values of all 17 anatomic landmarks of interest had an error no greater than $2 \mathrm{~mm}$, with a $95 \%$ confidence interval. For 14 variables, the differences between the parameters were statistically significant $(p<0.05)$, while for the right cheilion (Rt, ChSim, SD: 3.395636, $p=0.657182$ ), left cheilion (Lt, ChSim, SD: 3.193040, $p=0.704352$ ), and soft tissue B point (B'Sim, SD: 3.529335, $p=0.1779461$ ), despite deviations being significant $(p>0.05)$, the dispersions were clinically

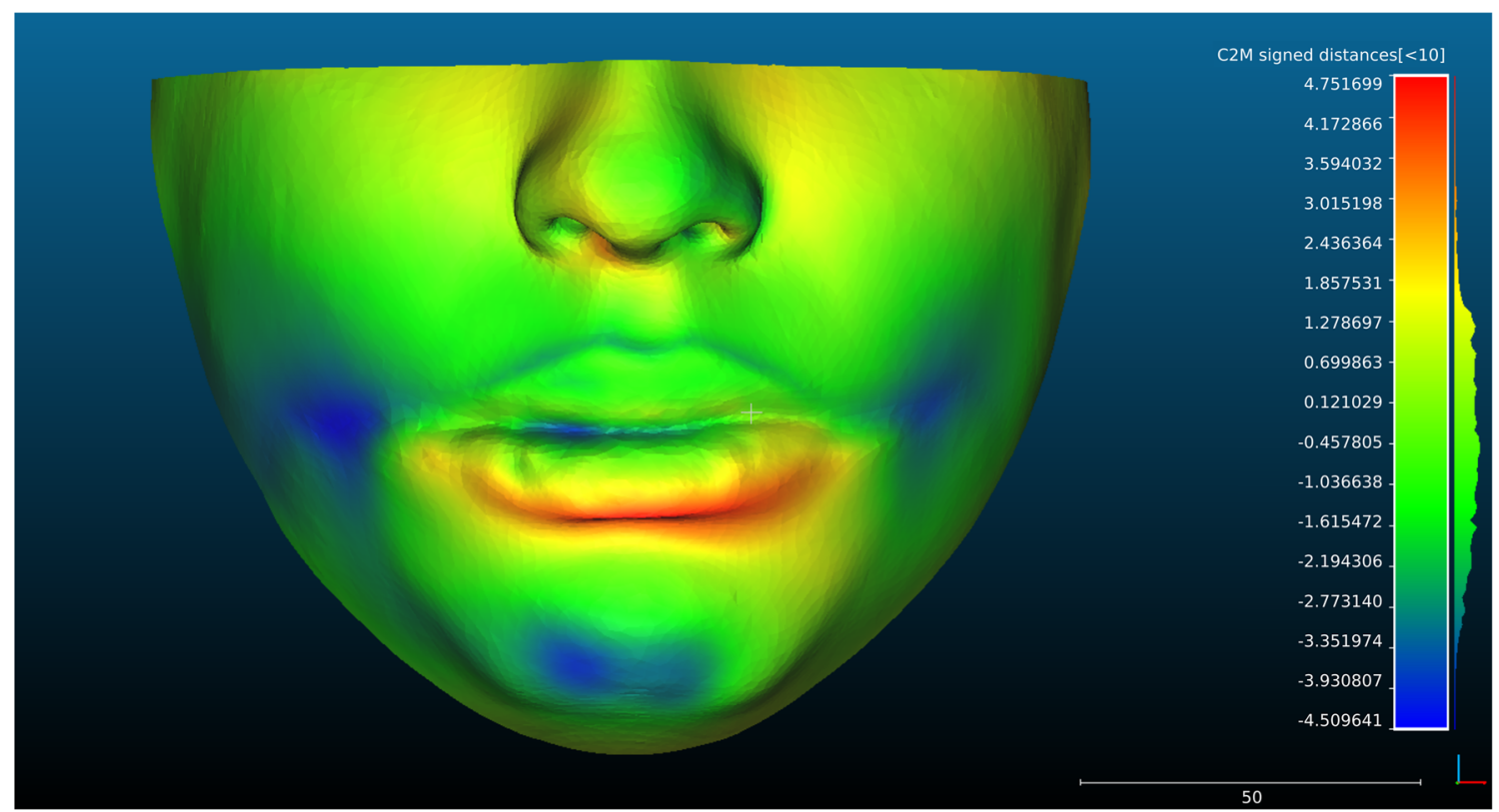

Fig. 9 Color distance map, prediction soft tissue mesh (M1) versus actual postoperative soft tissue mesh (M2) 
acceptable because the mean values obtained at these landmarks were below the reference constant (error $\leq 2 \mathrm{~mm}$ ).

The results showed an average error of less than $2 \mathrm{~mm}$ for all landmarks of interest and an overall mean error of $1.07 \mathrm{~mm}$ for the face as a whole. In agreement with these findings, previous studies have observed that a difference of $<2 \mathrm{~mm}$ between M1 and M2 meshes should be considered clinically acceptable $[3,15,46]$. The SurgiCase CMF® software was considered validated after two studies reported its accuracy for prediction of the overall face with a mean absolute error of $0.94 \mathrm{~mm}$ and $0.75 \mathrm{~mm}$, respectively. In light of this, the authors considered a predictability error of less than $2 \mathrm{~mm}$ to be insignificant and therefore sufficiently accurate for clinical applications [18, 47]. Likewise, Mundluru et al. [3] showed that the distances between the predicted and actual changes in soft tissues in the postoperative period were less than $2.0 \mathrm{~mm}$ $(p<0.05)$ in all regions of the face and that Maxilim ${ }^{\circledR}$ software yielded clinically acceptable 3D simulations for correction of asymmetric cases. Ullah [48], in a study of the 3dMD Vultus ${ }^{\circledR}$ software, considered the difference between the predictive mesh and the mesh of the actual postoperative soft tissue positions acceptable if the error was less than $3 \mathrm{~mm}$. Other authors, during their validations of the ability of software programs to predict facial soft tissue changes after orthognathic surgery, observed that the quantitative errors of distance between the patient's predicted and actual surfaces for the entire face and any subregions thereof were consistently less than $1.5 \mathrm{~mm}$. Kim et al. [17] conducted a quantitative and qualitative validation of a finite element model with nodal strength restriction in 40 cases, comparing it with the traditional finite element method. Quantitative errors in distance between the patients' predicted and actual surfaces for the entire face and any subregions thereof were $<1.5 \mathrm{~mm}$. The general predictive error for soft tissue changes in the face was $1.1 \pm 0.3 \mathrm{~mm}$. Qualitative validation also demonstrated the clinical viability of the tested approach. Kambay et al. [30] found that the mean linear distances between surfaces on the face was $\leq 0.8 \mathrm{~mm}$ but increased when the mean absolute distance was used. However, they stressed that comparison of specific anatomical regions is more clinically significant than that of the entire face.

In this study, the points with the greatest dispersion were Rt, ChSim $(p=0.657182)$, Lt, ChSim $(p=0.704352)$, and B'Sim $(p=0.1779461)$. Simulation of these landmarks was overcorrected in relation to their actual postoperative positions. They are topographically related to the right and left labial commissure (intersection of the lower and upper lip) and the most concave point on the curve between the lower lip skin and the soft tissue pogonion, respectively. Nevertheless, the means of these points (Rt, ChSim: $\bar{x}=$ 1.61563, SD, 3.395636; Lt, ChSim: $\bar{x}=1.69125 \pm \mathrm{SD}$, 3.193040 ; B'Sim: $\bar{x}=0.75750 \pm \mathrm{SD}, 3.529335$ ) were all consistent with an error of less than $2 \mathrm{~mm}$. Schendel et al. [28] found a mean difference of $0.27 \mathrm{~mm}$ between the simulated and real meshes of the soft tissue surface, the largest errors being associated with the upper and lower lip regions (0.9$1.10 \mathrm{~mm}$ ). Ullah [48], in a sample of 13 patients who underwent maxillary advancement (one-sample $t$ test), found that the distances between the predicted soft tissue and the actual postoperative soft tissue were within the stipulated $3 \mathrm{~mm}$ reference constant for all areas of interest $(p<0.05)$. The mean discrepancy between $90 \%$ of the mesh points was greater than $1 \mathrm{~mm}$ in the region of the labial commissures, using the $3 \mathrm{dMD}$ Vultus ${ }^{\circledR}$ program.

Figure 7 shows that the anatomical points with negative means were all short of the limits established by the M2 postoperative control mesh $(70.58 \%)$ : pronasale $(\mathrm{Pn})$; right exocanthus-alar base (Rt.Exo-Al); right cheek (Rt.Ck); right alar base (Rt.Al); left alar base (Lt.Al); left cheek (Lt.Ck); left exocanthus-alar base (Lt.Exo-Al); right cheilion-alar base (Rt.Ch-Al); right Cupid's bow (Rt.Cu); left Cupid's bow (Lt.Cu); left cheilion-alar base (Lt.Ch-Al); and soft tissue pogonion (Pog'). The positive values, i.e., those which in the simulation projected beyond the actual postoperative values obtained in mesh M2 (29.41\%), are represented by the points: subnasale $(\mathrm{Sn})$, right cheilion (Rt.Ch), left cheilion (Lt.Ch), lower lip (LL), and soft tissue B point ( $\left.\mathrm{B}^{\prime}\right)$. Despite small statistical variations, in all cases, simulated tissue advancement was consistent with the actual movement obtained postoperatively, i.e., the simulated movement was within an acceptable probability $(<2 \mathrm{~mm})$. Mundluru et al. [3] using Maxilim ${ }^{\circledR}$, reported a tendency toward underestimation of soft tissue changes in response to the correction of facial asymmetry in all anatomic regions, except for the upper lip and left cheek, where simulations instead appeared to overpredict the actual change. In addition in the area of the cheek and of the chin (medio-laterally), under prediction was depicted, and an overprediction of inferior border of the mandible (bilaterally) was shown. Knoops et al. [46] conducted a clinical comparison between the Dolphin ${ }^{\circledR}$ and ProPlan CMF® programs and a probabilistic finite element model (PFEM). The error between the soft tissue prediction and the postoperative mesh (both based on cone-beam CT images) showed good results for all three methods, with statistically significant superiority of ProPlan ${ }^{\circledR}$ and the PFEM compared to Dolphin ${ }^{\circledR}$. The Dolphin ${ }^{\circledR}$ software yielded better results in the midline and upper lip, while it underestimated soft tissue movements in the paranasal region due to the scarcity of reference landmarks in the algorithm database. On the other hand, predictions made with ProPlan $®$ and the probabilistic model showed continuous alignment with the postoperative mesh in the upper lip and paranasal region, although they were overcorrected in the area above the cheilion point (labial commissure). 
Close to the midline of the face, in the areas of the upper and lower lip, nose, and chin, the OOB simulation aligned continuously with the actual postoperative mesh, meaning that no variable showed a statistically significant deviation greater than $2 \mathrm{~mm}$ (Pn (pronasale): $\bar{x}=-0.78375+\mathrm{SD}, 1.642307$; Sn (subnasale): $\bar{x}=0.57938 \pm \mathrm{SD}, 1.846772$; Rt.Cu (right Cupid's bow): $\bar{x}=-0.96125 \pm$ SD, 2.062942; Lt.Cu (left Cupid's bow): $\bar{x}=-1.34750 \pm \mathrm{SD}, 1.899711$; LL (lower lip): $\bar{x}=0.59562 \pm \mathrm{SD}, 2.581834 ; \mathrm{B}^{\prime}$ (soft tissue point $\mathrm{B}$ ): $\bar{x}=$ $0.75750 \pm \mathrm{SD}, 3.529335$; Pog' (soft tissue pogonion): $\bar{x}=-$ $1.29312 \pm \mathrm{SD}, 2.110816)$. Among these variables, the one that showed the greatest dispersion was the $\mathrm{B}^{\prime}(p=0.1779461)$, but the deviation remained $<2 \mathrm{~mm}$. Comparatively, Knoops et al. [46] found that three software programs were accurate in simulating facial soft tissues (RMS Dolphin ${ }=1.8 \pm 0.8 \mathrm{~mm}$,

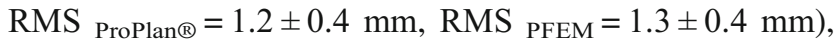
but the Dolphin ${ }^{\circledR}$ program had limited 3D accuracy, while ProPlan ${ }^{\circledR}$ and PFEM showed better 3D predictive ability. Dolphin ${ }^{\circledR}$ showed better predictive ability mainly in the $2 \mathrm{D}$ midline and upper lip, while soft tissue movements in the paranasal region were affected by greater error due to its algorithm. Similarly, Resnick et al. [29] using Dolphin ${ }^{\circledR}$ demonstrated the mean error at the nasolabial angle was $8.1 \pm 5.6^{\circ}$, showing low accuracy to predict $3 \mathrm{D}$ soft tissue changes after Le Fort I osteotomy.

Kim et al. [17] found a predictive error in the upper and lower lip regions of $1.2 \pm 0.7 \mathrm{~mm}$ and $1.5 \pm 0.7 \mathrm{~mm}$, respectively. However, the authors highlight the limitations of prediction in the lip area, noting that eight results were clinically deficient using the three-stage FEM method and that they are working to improve the method and increase accuracy in these anatomical regions.

Osteotomies such as Le Fort I are related to side effects of the nasolabial soft tissues including broadening of the alar base, vermilion and upper lip deficiency, and downsloping of the commissures [49]. The alar cinch suturing originally described by Millard [50] and V-Y lip closure technique by Schendel and Williamson [51] are related to correction of nasal widening and short/thin upper lip, respectively. Concerning to 3D nasal and lip soft tissue simulation, current software despite numerical calculation techniques find it difficult to reproduce the exact amount of movement given by these two suturing techniques considering non-linear nature of the hard tissue to soft tissue ratio for prediction of the soft tissue results, especially in the lip regions [18, 42]. However, Liebregts et al. [40] in a sample of 60 patients applied the alar cinch suturing technique on 22 patients and an upper lip augmentation with V-Y closure on 14 patients. The accuracy of the soft tissue simulation in the upper lip region was the highest $(1.2 \pm 0.6 \mathrm{~mm})$, whereas the lower lip region was the least predictable $(1.4 \pm 0.5 \mathrm{~mm})$. The mean error in soft tissue simulation among patients who had a V-Y closure $(0.7 \mathrm{~mm})$ was statistically smaller than those without a $\mathrm{V}-\mathrm{Y}$ closure $(0.8 \mathrm{~mm})$. However, this difference was not present with regard to the alar cinch suture. The accuracy of the soft tissue simulation decreased in patients with a larger surgical advancement and the use of V-Y closure. They concluded Mass Tensor Model-based soft tissue simulation (Maxilim ${ }^{\circledR}$ software) for bimaxillary surgery was accurate for clinical use, though patients should be informed of possible variation in the predicted lip position [40].

This study, using OOB shows all sixteen patients subjected to alar cinch suture and V-Y lip closure. Thereby eight reference points were directly influenced by these two techniques: Pn (pronasale): $\bar{x}=-0.78375+\mathrm{SD}, 1.642307 ; \mathrm{Sn}$ (subnasale): $\bar{x}=0.57938 \pm \mathrm{SD}, 1.846772$; Rt.Cu (right Cupid's bow): $\bar{x}=-0.96125 \pm$ SD, 2.062942; Lt.Cu (left Cupid's bow): $\bar{x}=-1.34750 \pm \mathrm{SD}, 1.899711$; Rt.Al (right alar base) $\bar{x}=-0.55125 \pm \mathrm{SD}, 1.849309$; Lt.Al (Left alar base) $\bar{x}=-0.65187 \pm 1.802865$. For the last two variables (right and left cheilion), there were statistically significant differences, but the discrepancy between the means was below the value of the reference constant (error $\leq 2 \mathrm{~mm}$ ) making the dispersions clinically acceptable (Rt.Ch (right cheilion): $\bar{x}=$ $1.61563 \pm \mathrm{SD}, 3.395636(p=0.657182)$; Lt.Ch (left cheilion): $\bar{x}=1.69125 \pm \mathrm{SD}, 3.193040(p=0.704352)$. Most variables had underestimated mean, except Sn (subnasale), Rt.Ch (right cheilion), and Lt.Ch (left cheilion) which had mean with overestimated pattern. These data indicate the need for studies on OOB comparing cases with and without alar cinch suture and $\mathrm{V}-\mathrm{Y}$ closure. One must consider the measurement of inter-alar width was not subject of this study.

\section{Study limitations}

The results depicted in this study allow us to infer that the OOB add-on can be considered an efficient tool for precise soft tissue virtual planning of orthognathic surgery. The level of statistical probability achieved is consistent with the data reported in prior studies [3, 17, 18, 28, 46, 48]. Furthermore, these data demonstrated the reliability of the method based on statistical probability herein demonstrated [52]. Despite OOB demonstrated high-level efficiency and accuracy, we recognize the limitations of the retrospective, non-randomized design of this study. Further prospective studies are therefore necessary to overcome the limitations inherent to retrospective studies. However, we point out that evidence-based protocols are challenging to develop [52]. An additional limitation concerns the small number of patients $(n=16)$ who were retrospectively included in the study, due to the strict inclusion criteria enforced to minimize variability. Thus, a larger sample size would be desirable for a prospective follow-up study, preferably one comparing the results of other software programs using different mesh deformation models to the model used in the present study. Literature has shown a variety of factors affecting the accuracy of predictions of soft tissue 
outcomes: gender, race, soft tissue thickness, mean ratios of soft tissue to hard tissue movements, biological factors, relapse, method-related factors (reproducibility in landmark identification and computer digitization), magnitude of skeletal repositioning, number of oral surgeons involved, presurgical orthodontics, condylar displacement, and mandibular center of rotation [53].

Although technical and scientific developments provide us with tools of increasing accuracy and precision, we remain limited by the idiosyncrasies of the soft tissues of each patient. Our study demonstrated an error of only very small magnitude between the M1 (simulated) mesh and the M2 (postoperative) mesh; any differences can be corrected or adjusted with tools such as Weight Paint in Blender [33]. However, the characteristics of facial soft tissues change with age (months and years) and are also subject to deformation by various forces and metabolic changes, the most relevant being gravity and body mass index, respectively. One study showed that soft tissue deformation of face due to gravity could range from 4 to $6 \mathrm{~mm}$ in a horizontal or vertical direction in two groups aged $25-35$ and 45-60, respectively [54]. Another study found that patients with signs of midfacial aging photographed in the supine position, as opposed to the upright position, appeared to have much more balance and volume in the periorbital region and midface itself. For participants who provided photographs taken 10 to 15 years earlier, the appearance of the facial volume was similar between these images and the current supine facial photographs. This suggests that the volume displacement due to gravitational forces plays a fundamental role in the morphogenesis of midface aging [55]. On the other hand, De Greef et al. [56] reported results confirming the dominant role of BMI in changes in thickness of the facial soft tissues. The tissue mass of the mouth and lower third of the face tends to decrease with age, whereas that of the chin and eyebrow may increase with age.

Another limiting factor concerns the soft tissues of the face during acquisition of $\mathrm{CT}$ images. In cone-beam $\mathrm{CT}$ scanners which have a smaller field of view, part of the soft tissues is suppressed in some cases (i.e.: nose tip) [38]. In addition, the patient may contract the soft tissues of the lips and chin region during the scan [28]. Although some authors have described models that allow realistic representation of the forcedeformation characteristics of soft tissues, 3D modeling of these complex anatomical tissues of the face still needs improvement $[45,54]$.

In view of the many variables involved, even with state-ofthe-art medical imaging, image analysis procedures, and the advanced numerical calculation techniques used to reconstruct a computational model of the face, accuracy is still hard to achieve [45]. This is why we will increasingly refer to "probability-based science." Cases of asymmetric deformities and those requiring vertical correction still pose a challenge, because simulation of facial soft tissue dynamics requires complex mathematical modeling of the mesh $[3,28]$. In this study, undercorrection error (negative values) was more prevalent, representing $70.58 \%$ of the total, as compared to overcorrection (positive values), which accounted for only $29.41 \%$ of error in relation to the postoperative mesh (M2). These data show that improvements in the mesh deformation methods of $\mathrm{OOB}$ are still required to increase precision in 3D simulation of the soft tissues of the face.

\section{Scientific evidence and probability: facing limits}

The terms precision and accuracy lead us to distinct concepts based on scientific evidence. The concept of precision was introduced by Newton when he began to explain the universe through mathematics (namely, the empirical propositions "ifthen" ("when-then"), "if-and-only-if." "When" is not "if." "When" suggests a certain assertiveness regarding the occurrence of the phenomenon, whereas "if" leaves the occurrence of the phenomenon as an open question) $[57,58]$.

The huge success of precision mathematics led scientists to expect that it was only a matter of time before a set of formulas was devised that would explain the entire universe. However, they soon realized that, as their measurement instruments became more accurate and precise, it was evident that their formulas were less accurate and precise in predicting natural phenomena [59]. This led to a paradigm shift: "In the modern scientific model, one can never predict when and how a phenomenon will happen; we can only calculate its probability" $[59,60]$. The scientific mathematics of today recognizes uncertainty; it is a mathematics of probability [59]. One can speak of "hypotheses" instead of "diagnoses," thus changing the expectations of patients and health professionals alike and facilitating a conceptual change [61]. We are now facing this hypothesis challenge with the COVID-19 pandemic, where physician investigators and public health services worldwide are trying to find a successful approach to fight the novel coronavirus [53]. To date, there are no specific vaccines or medicines for COVID-19. Treatments are under investigation and will be tested through clinical trials $[62,63]$.

\section{OOB in translational research}

When only conventional 2D treatment was available and access to proprietary $3 \mathrm{D}$ software was greatly restricted, the probabilities of treatment outcomes were exceedingly difficult to estimate. Furthermore, CBCT scanners and virtual 3D software packages remain very expensive. In 2009, Swennen et al. [64], emphasizing the importance of translational research, stated: "Hence, the challenge and common goal is to develop 3D virtual treatment planning of orthognathic surgery as an efficient and cost-effective clinical tool that improves the care of the patient with a maxillofacial deformity". Within this context, the use of free and open-source software provides a 
greater number of practitioners and patients with access to visualization of surgical planning through virtual simulation methods. Furthermore OOB aiming to still contribute to translational science has developed 3D customization of medical protective equipment in COVID-19 pandemic [65].

\section{Conclusion}

Statistical analysis of comparison between meshes simulated preoperatively (M1) and meshes reconstructed from postoperative CT scans (M2) revealed statistically and clinically significant ability (error $<2 \mathrm{~mm}$ ) to reproduce real surgical movement. OOB is capable of accurate soft tissue planning for orthognathic surgery, but mesh deformation methods still require improvement.

Acknowledgments All authors thank Heury Sousa Ferreira, PhD, senior consultant at Yalo scientific and statistical consultancy for the statistical analysis and to Scientific Linguagem for the specialized English support.

Author contribution Conception and design: HSC, CACM, ELSR

Data collection: HSC, RFVD

Analysis and interpretation: HSC, CACM, RFVD, ELSR

Writing the article: HSC, CACM, RFVD, ELSR

Critical revision of the article: HSC, CACM, RFVD, ELSR

Overall responsibility: The corresponding author assumes overall responsibility for the manuscript.

All authors have read and approved the final version of the article.

\section{Compliance with ethical standards}

Conflict of interest The authors declare that they have no conflict of interest.

Ethics approval The study protocol was submitted to and approved by the Instituto de Gestão Estratégica de Saúde do Distrito Federal (IGESDF) Research Ethics Committee (CAAE:12203819.8.0000.8153) with opinion number 3.732.163 and by Plataforma Brasil www.saude. gov.br/plataformabrasil). All procedures performed in this study were in accordance with the ethical standards of the institutional and National Research Committee and with the 1964 Helsinki declaration and its later amendments or comparable ethical standards.

Consent to participate Informed consent was obtained from all individual participants included in the study.

Code availability Blender is a free and open-source software with internet accessibility (Blender Foundation, https://www.blender.org/) and uses Python programming language. OOB in turn uses Blender as base hosting and runs on Microsoft Windows, Mac OS X, and Linux. OOB is an orthognathic surgery planning add-on created by Cicero Moraes, Everton da Rosa, and Rodrigo Dornelles.

\section{References}

1. Soncul M, Bamber MA (2004) Evaluation of facial soft tissue changes with optical surface scan after surgical correction of class
III deformities. J Oral Maxillofac Surg 62(11):1331-1340. https:// doi.org/10.1016/j.joms.2004.04.019

2. Baik HS, Kim SY (2010) Facial soft-tissue changes in skeletal class III orthognathic surgery patients analyzed with 3-dimensional laser scanning. Am J Orthod Dentofac Orthop 138(2):167-178. https:// doi.org/10.1016/j.ajodo.2010.02.022

3. Mundluru T, Almukhtar A, Ju X, Ayoub A (2017) The accuracy of three-dimensional prediction of soft tissue changes following the surgical correction of facial asymmetry: an innovative concept. Int $\mathrm{J}$ Oral Maxillofac Surg 46(11):1517-1524. https://doi.org/10.1016/j. ijom.2017.04.017

4. Kim BR, Oh KM, Cevidanes LH, Park JE, Sim HS, Seo SK, Reyes M, Kim YJ, Park YH (2013) Analysis of 3D soft tissue changes after 1- and 2-jaw orthognathic surgery in mandibular prognathism patients. J Oral Maxillofac Surg 71(1):151-161. https://doi.org/10. 1016/j.joms.2012.02.005

5. Ryckman MS, Harrison S, Oliver D, Sander C, Boryor AA, Hohmann AA, Kilic F, Kim KB (2010) Soft-tissue changes after maxillomandibular advancement surgery assessed with cone-beam computed tomography. Am J Orthod Dentofac Orthop 137(4 Suppl):S86-S93. https://doi.org/10.1016/j.ajodo.2009.03.041

6. Lim YK, Chu EH, Lee DY, Yang IH, Baek SH (2010) Threedimensional evaluation of soft tissue change gradients after mandibular setback surgery in skeletal class III malocclusion. Angle Orthod 80(5):896-903. https://doi.org/10.2319/021210-90.1

7. Sarver DM (1998) Esthetic orthodontics and orthognathic surgery. Mosby, Michigan

8. Eckhardt CE, Cunningham SJ (2004) How predictable is orthognathic surgery? Eur J Orthod 26(3):303-309. https://doi. org/10.1093/ejo/26.3.303

9. Kaplan B, Lundsgaarde HP (1996) Toward an evaluation of an integrated clinical imaging system: identifying clinical benefits. Methods Inf Med 35(3):221-229

10. Grubb JE, Smith T, Sinclair P (1996) Clinical and scientific applications/advances in video imaging. Angle Orthod 66(6): 407-416. https://doi.org/10.1043/0003-3219(1996)066<0407: CASAAI $>2.3 . \mathrm{CO} ; 2$

11. Phillips C, Bailey L, Kiyak HA, Bloomquist D (2001) Effects of a computerized treatment simulation on patient expectations for orthognathic surgery. Int J Adult Orthodon Orthognath Surg 16(2):87-98

12. Ryan FS, Barnard M, Cunningham SJ (2012) What are orthognathic patients' expectations of treatment outcome - a qualitative study. J Oral Maxillofac Surg 70(11):2648-2655. https:// doi.org/10.1016/j.joms.2012.01.002

13. Donatsky O, Bjorn-Jorgensen J, Holmqvist-Larsen M, Hillerup S (1997) Computerized cephalometric evaluation of orthognathic surgical precision and stability in relation to maxillary superior repositioning combined with mandibular advancement or setback. J Oral Maxillofac Surg 55(10):1071-1079; discussion 1079-1080. https://doi.org/10.1016/s0278-2391(97)90282-2

14. Almeida RC, Cevidanes LH, Carvalho FA, Motta AT, Almeida MA, Styner M, Turvey T, Proffit WR, Phillips C (2011) Soft tissue response to mandibular advancement using 3D CBCT scanning. Int J Oral Maxillofac Surg 40(4):353-359. https://doi.org/10.1016/j. ijom.2010.11.018

15. Chapuis J, Schramm A, Pappas I, Hallermann W, SchwenzerZimmerer K, Langlotz F, Caversaccio M (2007) A new system for computer-aided preoperative planning and intraoperative navigation during corrective jaw surgery. IEEE Trans Inf Technol Biomed 11(3):274-287. https://doi.org/10.1109/titb.2006.884372

16. Hajeer MY, Ayoub AF, Millett DT (2004) Three-dimensional assessment of facial soft-tissue asymmetry before and after orthognathic surgery. Br J Oral Maxillofac Surg 42(5):396-404. https://doi.org/10.1016/j.bjoms.2004.05.006 
17. Kim D, Ho DC, Mai H, Zhang X, Shen SGF, Shen S, Yuan P, Liu S, Zhang G, Zhou X, Gateno J, Liebschner MAK, Xia JJ (2017) A clinically validated prediction method for facial soft-tissue changes following double-jaw surgery. Med Phys 44(8):4252-4261. https:// doi.org/10.1002/mp.12391

18. Bianchi A, Muyldermans L, Di Martino M, Lancellotti L, Amadori S, Sarti A, Marchetti C (2010) Facial soft tissue esthetic predictions: validation in craniomaxillofacial surgery with cone beam computed tomography data. J Oral Maxillofac Surg 68(7):1471-1479. https:// doi.org/10.1016/j.joms.2009.08.006

19. Ayoub AF, Wray D, Moos KF, Siebert P, Jin J, Niblett TB, Urquhart C, Mowforth R (1996) Three-dimensional modeling for modern diagnosis and planning in maxillofacial surgery. Int $\mathrm{J}$ Adult Orthodon Orthognath Surg 11(3):225-233

20. Ayoub AF, Siebert P, Moos KF, Wray D, Urquhart C, Niblett TB (1998) A vision-based three-dimensional capture system for maxillofacial assessment and surgical planning. Br J Oral Maxillofac Surg 36(5):353-357. https://doi.org/10.1016/s0266-4356(98) 90646-5

21. Keeve E, Girod S, Kikinis R, Girod B (1998) Deformable modeling of facial tissue for craniofacial surgery simulation. Comput Aided Surg 3(5):228-238. https://doi.org/10.1002/(SICI)10970150(1998)3:5<228::AID-IGS2>3.0.CO;2-I

22. Xia J, Wang D, Samman N, Yeung RW, Tideman H (2000) Computer-assisted three-dimensional surgical planning and simulation: 3D color facial model generation. Int J Oral Maxillofac Surg 29(1):2-10

23. Xia J, Samman N, Yeung RW, Wang D, Shen SG, Ip HH, Tideman H (2000) Computer-assisted three-dimensional surgical planning and simulation. 3D soft tissue planning and prediction. Int $\mathrm{J}$ Oral Maxillofac Surg 29(4):250-258

24. Xia J, Ip HH, Samman N, Wang D, Kot CS, Yeung RW, Tideman $\mathrm{H}$ (2000) Computer-assisted three-dimensional surgical planning and simulation: 3D virtual osteotomy. Int J Oral Maxillofac Surg 29(1):11-17

25. Xia J, Samman N, Chua CK, Yeung RWK, Wang D, Shen SG, Ip $\mathrm{HH}$, Tideman H (2000) PC-based virtual reality surgical simulation for orthognathic surgery. In: Delp SL, DiGoia AM, Jaramaz B (eds) Medical image computing and computer-assisted intervention MICCAI 2000. MICCAI 2000. Lecture Notes in Computer Science, vol 1935. Springer, Berlin. https://doi.org/10.1007/9783-540-40899-4 106

26. Olivetti EC, Nicotera S, Marcolin F, Vezzetti E, Sotong JPA, Zavattero E, Ramieri G (2019) 3D soft-tissue prediction methodologies for orthognathic surgery-a literature review. Appl Sci 9: 4550. https://doi.org/10.3390/app9214550

27. Mollemans W, Schutyser F, Nadjmi N, Suetens P (2005) Very fast soft tissue predictions with mass tensor model for maxillofacial surgery planning systems. Int Congr Ser 1281:491-496. https:// doi.org/10.1016/j.ics.2005.03.048

28. Schendel SA, Jacobson R, Khalessi S (2013) 3-dimensional facial simulation in orthognathic surgery: is it accurate? J Oral Maxillofac Surg 71(8):1406-1414. https://doi.org/10.1016/j.joms.2013.02.010

29. Resnick CM, Dang RR, Glick SJ, Padwa BL (2017) Accuracy of three-dimensional soft tissue prediction for Le Fort I osteotomy using Dolphin 3D software: a pilot study. Int J Oral Maxillofac Surg 46(3):289-295. https://doi.org/10.1016/j.ijom.2016.10.016

30. Khambay B, Ullah R (2015) Current methods of assessing the accuracy of three-dimensional soft tissue facial predictions: technical and clinical considerations. Int J Oral Maxillofac Surg 44(1): 132-138. https://doi.org/10.1016/j.ijom.2014.04.007

31. Mollemans W, Schutyser F, Van Cleynenbreugel J, Suetens P (2004) Fast soft tissue deformation with tetrahedral mass spring model for maxillofacial surgery planning systems. In: International Conference on Medical Image Computing and
Computer-Assisted Intervention Springer, Berlin, pp 371-379. https://doi.org/10.1007/978-3-540-30136-3_46

32. Mollemans W, Schutyser F, Nadjmi N, Maes F (2006) 3D soft tissue predictions with a tetrahedral mass tensor model for a maxillofacial planning system: a quantitative validation study. In: Proceedings of SPIE - The International Society for Optical Engineering, vol 6141. https://doi.org/10.1117/12.653063

33. Moraes C (2019) OrtogonBlender: an open-source software add-on for dental and maxillofacial applications 3rd ed. Edn Publisher: Cicero André da Costa Moraes SINOP-MT, 335p. https://doi.org/ 10.6084/m9.figshare.12871730.v1

34. Houston Metodist Leading Medicine (2020) ANATOMICALIGNER. https://www.houstonmethodist.org/ anatomicaligner/. Accessed 10 May 2020

35. Jayaratne YS, Zwahlen RA, Lo J, Cheung LK (2010) Threedimensional color maps: a novel tool for assessing craniofacial changes. Surg Innov 17(3):198-205. https://doi.org/10.1177/ 1553350610370752

36. Bianchi G, Solenthaler B, Székely G, Harders M (2004) Simultaneous topology and stiffness identification for massspring models based on FEM reference deformations. In, Berlin, Heidelberg, 2004. Medical image computing and computerassisted intervention - MICCAI 2004. Springer Berlin Heidelberg, pp 293-301. https://doi.org/10.1007/978-3-54030136-3_37

37. Mollemans W, Schutyser F, Nadjmi N, Maes F, Suetens P (2007) Predicting soft tissue deformations for a maxillofacial surgery planning system: from computational strategies to a complete clinical validation. Med Image Anal 11(3):282-301. https://doi.org/10. 1016/j.media.2007.02.003

38. Moraes CAC (2019) CT Scan protocol for orthognathic surgery planning. http://www.ciceromoraes.com.br/doc/pt_br/ OrtogOnBlender/Tomografia.html. Accessed 15 February 2020

39. Real FH (2018) Three-dimensional assessment of condylar changes after surgery first. Thesis Universidade Federal do Pará (UFPA)

40. Liebregts J, Xi T, Timmermans M, de Koning M, Berge S, Hoppenreijs T, Maal T (2015) Accuracy of three-dimensional soft tissue simulation in bimaxillary osteotomies. J Craniomaxillofac Surg 43(3):329-335. https://doi.org/10.1016/j.jcms.2014.12.012

41. Traisrisin K, Wangsrimongkol T, Pisek P, Rattanaphan P, Puasiri S (2017) The accuracy of soft tissue prediction using Morpheus 3D simulation software for planning orthognathic surgery. J Med Assoc Thail 100(Suppl 6):S38-S49

42. Marchetti C, Bianchi A, Muyldermans L, Di Martino M, Lancellotti L, Sarti A (2011) Validation of new soft tissue software in orthognathic surgery planning. Int J Oral Maxillofac Surg 40(1): 26-32. https://doi.org/10.1016/j.ijom.2010.09.004

43. Abe N, Kuroda S, Furutani M, Tanaka E (2015) Data-based prediction of soft tissue changes after orthognathic surgery: clinical assessment of new simulation software. Int J Oral Maxillofac Surg 44(1):90-96. https://doi.org/10.1016/j.ijom.2014.08.006

44. Holzinger D, Juergens P, Shahim K, Reyes M, Schicho K, Millesi G, Perisanidis C, Zeilhofer HF, Seemann R (2018) Accuracy of soft tissue prediction in surgery-first treatment concept in orthognathic surgery: a prospective study. J Craniomaxillofac Surg 46(9):14551460. https://doi.org/10.1016/j.jcms.2018.05.055

45. Mazza E, Barbarino GG (2011) 3D mechanical modeling of facial soft tissue for surgery simulation. Facial Plast Surg Clin North Am 19(4):623-637, viii. https://doi.org/10.1016/j.fsc.2011.07.006

46. Knoops PGM, Borghi A, Breakey RWF, Ong J, Jeelani NUO, Bruun R, Schievano S, Dunaway DJ, Padwa BL (2019) Threedimensional soft tissue prediction in orthognathic surgery: a clinical comparison of Dolphin, ProPlan CMF, and probabilistic finite element modelling. Int J Oral Maxillofac Surg 48(4):511-518. https:// doi.org/10.1016/j.ijom.2018.10.008 
47. Marchetti C, Bianchi A, Bassi M, Gori R, Lamberti C, Sarti A (2007) Mathematical modeling and numerical simulation in maxillofacial virtual surgery. J Craniofac Surg 18(4):826-832. https:// doi.org/10.1097/scs.0b013e318068434b

48. Ullah R (2014) The validity of 3dMD Vultus in predicting soft tissue morphology following orthognathic surgery. Thesis, University of Birmingham

49. Muradin MS, Rosenberg AJ, van der Bilt A, Stoelinga PJ, Koole R (2012) The influence of a Le Fort I impaction and advancement osteotomy on smile using a modified alar cinch suture and V-Y closure: a prospective study. Int J Oral Maxillofac Surg 41(5): 547-552. https://doi.org/10.1016/j.ijom.2011.08.011

50. Millard DR Jr (1980) The alar cinch in the flat, flaring nose. Plast Reconstr Surg 65(5):669-672. https://doi.org/10.1097/00006534198005000-00020

51. Schendel SA, Williamson LW (1983) Muscle reorientation following superior repositioning of the maxilla. J Oral Maxillofac Surg 41(4):235-240. https://doi.org/10.1016/0278-2391(83)90265-3

52. Sim I (1997) Trial banks: an informatics foundation for evidence based medicine. Dissertation, Stanford University. http://infolab. stanford.edu/pub/cstr/reports/cs/tr/97/1599/CS-TR-97-1599.pdf. Accessed 10 March 2020

53. Kolokitha OE, Chatzistavrou E (2012) Factors influencing the accuracy of cephalometric prediction of soft tissue profile changes following orthognathic surgery. J Maxillofac Oral Surg 11(1):8290. https://doi.org/10.1007/s12663-011-0253-6

54. Iblher N, Gladilin E, Stark BG (2013) Soft-tissue mobility of the lower face depending on positional changes and age: a threedimensional morphometric surface analysis. Plast Reconstr Surg 131(2):372-381. https://doi.org/10.1097/PRS.0b013e318278d67c

55. Mally P, Czyz CN, Wulc AE (2014) The role of gravity in Periorbital and Midfacial aging. Aesthet Surg J 34(6):809-822. https://doi.org/10.1177/1090820X14535077

56. De Greef S, Vandermeulen D, Claes P, Suetens P, Willems G (2009) The influence of sex, age and body mass index on facial soft tissue depths. Forensic Sci Med Pathol 5(2):60-65. https://doi. org/10.1007/s12024-009-9085-9
57. Cohen IB (1971) Introduction to Newton's 'principia'. Harvard University Press. Pp. xxviii, 380p In: The Journal of Modern History 46(1). https://doi.org/10.1086/241172

58. Sapunaru RA (2006) The Newtonian style, the space, the time and the movement absolutes: controversies between Cartesians and Newtonians. Dissertation, Pontifícia Universidade Católica do Rio de Janeiro (PUC-RIO). https://www.maxwell.vrac.puc-rio.br/ projetosEspeciais/ETDs/consultas/conteudo.php?strSecao= resultado\&nrSeq=8013@2. Accessed 28 March 2020

59. Correia LCL, Correia VCA (2017) A incerteza da medicina de precisão. Rev Educ Saúde 5(1):1-5. https://doi.org/10.29237/ 2358-9868.2017v5i1.p1-5

60. Capra F (1983) The turning point: science, society, and the rising culture. Bantam Books, New York

61. Simpkin AL, Schwartzstein RM (2016) Tolerating uncertainty - the next medical revolution? N Engl J Med 375(18):1713-1715. https://doi.org/10.1056/NEJMp1606402

62. Dong L, Hu S, Gao J (2020) Discovering drugs to treat coronavirus disease 2019 (COVID-19). Drug Discov Ther 14(1):58-60. https:// doi.org/10.5582/ddt.2020.01012

63. World Health Organization (WHO) (2020) Public advice. https:// www.who.int/health-topics/coronavirus\#tab=tab_1. Accessed 17 May 2020

64. Swennen GR, Mollemans W, Schutyser F (2009) Threedimensional treatment planning of orthognathic surgery in the era of virtual imaging. J Oral Maxillofac Surg 67(10):2080-2092. https://doi.org/10.1016/j.joms.2009.06.007

65. Moraes C, da Rosa ELS, Dornelles RFV (2020) OrtogOnBlender Project: a contribution to modeling custom masks in preventing Covid-19. https://www.researchgate.net/publication/340878584 A_Contribution_to_Modeling_Custom_Masks_in_Preventing CÖVID-19. Accessed 06 May 2020

Publisher's note Springer Nature remains neutral with regard to jurisdictional claims in published maps and institutional affiliations. 